\title{
Identification of key genes and associated pathways in KIT/PDGFRA wild-type gastrointestinal stromal tumors through bioinformatics analysis
}

\author{
WEN-JIE WANG ${ }^{1,2^{*}}$, HONG-TAO LI ${ }^{1,2^{*}}$, JIAN-PING YU ${ }^{1,2^{*}}$, YU-MIN LI $^{1}$, XIAO-PENG HAN ${ }^{1,2}$, \\ PENG CHEN ${ }^{2,3}$, WEN-WEN YU ${ }^{2}$, WEI-KAI CHEN ${ }^{2,3}$, ZUO-YI JIAO ${ }^{1}$ and HONG-BIN LIU ${ }^{1,2}$ \\ ${ }^{1}$ Second Clinical Medical College, Lanzhou University, Lanzhou, Gansu 730030; ${ }^{2}$ Department of General Surgery, \\ Lanzhou General Hospital of Chinese People's Liberation Army, Lanzhou, Gansu 730050; ${ }^{3}$ Clinical Medical College, \\ Gansu University of Chinese Medicine, Lanzhou, Gansu 730000, P.R. China
}

Received February 21, 2018; Accepted August 23, 2018

DOI: $10.3892 / \mathrm{mmr} .2018 .9457$

\begin{abstract}
Gastrointestinal stromal tumors (GISTs) are the most common type of mesenchymal tumor in the gastrointestinal tract. The present study aimed to identify the potential candidate biomarkers that may be involved in the pathogenesis and progression of v-kit Hardy-Zuckerman 4 feline sarcoma viral oncogene homolog (KIT)/platelet-derived growth factor receptor $\alpha$ (PDGFRA) wild-type GISTs. A joint bioinformatics analysis was performed to identify the differentially expressed genes (DEGs) in wild-type GIST samples compared with KIT/PDGFRA mutant GIST samples. Gene Ontology function and Kyoto Encyclopedia of Genes and Genomes (KEGG) pathway enrichment analysis of DEGs was conducted using Database for Annotation, Visualization and Integrated Discovery and KEGG Orthology-Based Annotation System (KOBAS) online tools, respectively. Protein-protein interaction (PPI) networks of the DEGs were constructed using Search Tool for the Retrieval of Interacting Genes online tool and Cytoscape, and divided into sub-networks using the Molecular Complex Detection (MCODE) plug-in. Furthermore, enrichment analysis of DEGs in the modules was analyzed with
\end{abstract}

Correspondence to: Professor Hong-Bin Liu, Department of General Surgery, Lanzhou General Hospital of Chinese People's Liberation Army, 333 Binhe South Road, Qilihe, Lanzhou, Gansu 730050, P.R. China

E-mail: liuhongbin999@163.com

Professor Zuo-Yi Jiao, Second Clinical Medical College, Lanzhou University, 82 Chuiying Gate, Chengguan, Lanzhou, Gansu 730030, P.R. China

E-mail: jiaozy@lzu.edu.cn

${ }^{*}$ Contributed equally

Key words: gastrointestinal stromal tumors, v-kit Hardy-Zuckerman 4 feline sarcoma viral oncogene homolog, PDGFRA, wild type, bioinformatics analysis, microarray
KOBAS. In total, 546 DEGs were identified, including 238 upregulated genes primarily enriched in 'cell adhesion', 'biological adhesion', 'cell-cell signaling', 'PI3K-Akt signaling pathway' and 'ECM-receptor interaction', while the 308 downregulated genes were predominantly involved in 'inflammatory response', 'sterol metabolic process' and 'fatty acid metabolic process', 'small GTPase mediated signal transduction', 'cAMP signaling pathway' and 'proteoglycans in cancer'. A total of 25 hub genes were obtained and four modules were mined from the PPI network, and sub-networks also revealed these genes were primarily involved in significant pathways, including 'PI3K-Akt signaling pathway', 'proteoglycans in cancer', 'pathways in cancer', 'Rap1 signaling pathway', 'ECM-receptor interaction', 'phospholipase D signaling pathway', 'ras signaling pathway' and 'cGMP-PKG signaling pathway'. These results suggested that several key hub DEGs may serve as potential candidate biomarkers for wild-type GISTs, including phosphatidylinositol-4,5-bisphosphate 3-kinase, catalytic subunit $\gamma$, insulin like growth factor 1 receptor, hepatocyte growth factor, thrombospondin 1, Erb-B2 receptor tyrosine kinase 2 and matrix metallopeptidase 2. However, further experiments are required to confirm these results.

\section{Introduction}

Gastrointestinal stromal tumors (GISTs) are the most common type of mesenchymal tumor in the gastrointestinal tract, which account for $20 \%$ of all soft-tissue sarcomas $(1,2)$. GISTs originate from the interstitial cells of Cajal, and may occur in any part of the gastrointestinal tract; the most frequent sites of origin are the stomach (50-60\%), followed by the small intestine $(30-35 \%)$, the colon and rectum (5\%), and finally the esophagus $(<1 \%)$ (3-5). The number of newly diagnosed GISTs is increasing yearly, since the identification of v-kit Hardy-Zuckerman 4 feline sarcoma viral oncogene homolog (KIT) and platelet-derived grow th factor receptor $\alpha$ (PDGFRA) proteins as reliable biomarkers of these tumors $(6,7)$.

Approximately $75-80 \%$ of GISTs have KIT gene mutations in exons 9, 11, 13, 14 and 17 . Of the remaining GISTs 
with no detected KIT mutations, $\sim 1 / 3$ have mutations in the PDGFRA gene, in exons 12, 14 and 18 (8). While the majority of GISTs are characterized by KIT/PDGFRA gene mutations, $10-15 \%$ of GISTs lack such mutations and are defined as KIT/PDGFRA wild-type GISTs $(9,10)$. KIT-also known as CD117 or C-kit receptor-encodes the c-KIT type III receptor tyrosine kinase, which is a cytokine receptor located on the surface of hematopoietic stem cells, as well as other cell types (11). PDGFRA-also known as PDGFR $\alpha$ - is also a type III receptor tyrosine kinase that is expressed on the surfaces of a wide range of cell types (12). Mutations in the PDGFRA gene may induce activation of constitutive ligand-independent kinases and are mutually exclusive with KIT gene mutations, i.e., KIT and PDGFRA mutations do not coexist in patients with GISTs (8). Imatinib, a small molecule selective tyrosine kinase inhibitor, has been used to treat KIT/PDGFRA mutated GISTs (1); however, the efficacy of imatinib depends on the mutated domains of KIT/PDGFRA. It has been reported that $\sim 10 \%$ of patients with GISTs are resistant to imatinib, and $40-50 \%$ of imatinib-sensitive patients will develop secondary resistance in 2 years (13). In addition, wild-type GISTs are resistant to imatinib treatment and the genetic alterations in wild-type GISTs remain unclear (8). Therefore, it is necessary to identify new target molecules that may be involved in the development and progression of wild-type GISTs.

Currently, gene profiling is widely used in the field of cancer genetics research, which is particularly suitable for the differentially expressed gene (DEG) screening. A large amount of gene profile data has been generated, and most of the data has been shared in public databases. Reintegrating these public data may provide valuable clues for further research. Although many gene profile studies have been performed on GISTs in recent years, research regarding wild-type GISTs is limited and the results are not consistent. Therefore, a joint bioinformatics analysis will be innovative and may provide valuable clues for further research.

In the present study, a joint bioinformatics analysis of two gene expression profiles was performed, in order to identify potential genetic changes in wild-type GIST samples compared to KIT/PDGFRA-mutant GIST samples. Subsequently, functional and pathway enrichment analyses were performed on the DEGs to identify potential biological functions and signaling pathways. Furthermore, a protein-protein interaction (PPI) network was constructed to identify key hub genes. The aim of the current study was to investigate the underlying biological functions and pathways involved in the development and progression of GISTs, and to identify potential candidate biomarkers for these tumors.

\section{Materials and methods}

Microarray data. The raw gene expression profiles (GSE17743 and GSE20708) were downloaded from the public Gene Expression Omnibus database (www.ncbi.nlm.nih.gov/geo), which were based on the GPL570 platform (Affymetrix Human Genome U133 Plus 2.0 Array; Thermo Fisher Scientific, Inc., Waltham, MA, USA), and were submitted by Ostrowski et al (14) and Astolfi et al (15), respectively. The GSE17743 dataset contained 29 GIST samples, including
15 with KIT mutations detected, 11 with PDGFRA mutations detected, and three with no mutations detected. The GSE20708 dataset included 22 GIST tumor samples, including 13 with KIT mutations detected, five with PDGFRA mutations detected, and four with no mutations detected. Thus, a total of 51 GIST tumor samples were used for further analysis in the present study.

Data processing. Samples ( $\mathrm{n}=51)$ were divided into two groups, including wild-type GIST groups $(n=7)$ and KIT/PDGFRA mutant GIST groups $(n=44)$. The CEL files were first converted into probe expression values and were preprocessed for background adjustment and quantile normalization by robust multiarray average algorithm using the 'affy' package in $\mathrm{R}$ (version 3.4.2) (16,17). The 'sva' package in $\mathrm{R}$ was used to remove batch effects between two gene expression profiles (18). The 'Hclust' method of R was used to perform cluster analysis for gene expression alterations at two batch levels (19). Following this, the probe-level data were transformed to the expression values of genes according to the latest version of annotation file (HG-U133_Plus_2; release 35) for Affymetrix Human Genome U133 Plus 2.0 Array, which was obtained from the official website (www.affymetrix.com/support/technical/byproduct. affx?product=hg-u133-plus). If one gene symbol was matched by multiple probes, then the average expression value was calculated for this gene.

Identification of DEGs. The 'limma' package (version 3.26.9) in $\mathrm{R}$ language was used to identify DEGs between two groups (20). Fold change (FC) of the gene expression was also observed and $\log _{2} \mathrm{FC}$ was calculated. The threshold was defined as a $\log _{2} \mathrm{FCl}$ of $>1$ and an adjusted P-value of $<0.05$. Hierarchical clustering analysis was subsequently performed using the 'pheatmap' package in R (21).

Functional and pathway enrichment analysis. Gene Ontology (GO) enrichment analysis and functional annotation of DEGs were performed using the Database for Annotation, Visualization and Integrated Discovery (DAVID) network software version 6.8 (https://david.ncifcrf.gov/) (22), and enriched GO terms were visualized using the BiNGO plug-in of Cytoscape software (version 3.5.1) (23). Kyoto Encyclopedia of Genes and Genomes (KEGG) enrichment analysis and functional annotation were processed by KEGG Orthology-Based Annotation System (KOBAS) network software version 3.0 (kobas.cbi.pku.edu.cn/download.php) (24). An adjusted P-value $<0.05$ was set as the cut-off criterion.

PPI network construction and modules selection. The PPI networks of DEGs were identified using the Search Tool for the Retrieval of Interacting Genes (STRING) database (string-db.org; release 10) (25). Interactions with confidence scores of $\geq 0.4$ were selected as significant and visualized using Cytoscape software (www.cytoscape.org) (26). The hub genes were selected by the cytoHubba plug-in, with $\geq 10$ degrees for each gene (27), and also mapped into ClueGO to visualize functionally grouped GO terms and KEGG pathway annotation networks (28). The Molecular Complex Detection (MCODE) plug-in was applied to screen modules of the PPI network with degree cutoff $=2$, node score cutoff $=0.2$, $\mathrm{k}$-core $=2$, and $\max$. 
depth=100 (29). Subsequently, the functional and pathway enrichment analysis of genes in each module (MCODE score $\geq 6$ and number of nodes $\geq 6$ ) was performed by KOBAS.

\section{Results}

Identification of DEGs. As presented in Fig. 1, the batch effects between two gene expression profiles datasets were removed. The data was normalized prior to further analysis (Fig. 2A and B). In total, 546 DEGs (238 upregulated DEGs and 308 downregulated DEGs) were identified in wild-type GIST samples, compared with KIT/PDGFRA mutant GIST samples, based on the cut-off criteria. The volcano plot (Fig. 2C) and heatmap (Fig. 3) demonstrated the distribution and cluster of DEGs, respectively.

Functional and pathway enrichment analysis. The directed acyclic graph of GO enrichment analysis and functional annotation of DEGs is depicted in Fig. 4. For biological processes (BP), the upregulated DEGs were primarily enriched in 'cell adhesion', 'biological adhesion' and 'synapse organization' (Table I; Fig. 5A and B); the downregulated DEGs were primarily enriched in 'sterol metabolic process', 'inflammatory response', and 'integrin-mediated signaling pathway' (Table I; Fig. 5C and D). For cellular component (CC), the upregulated DEGs were primarily enriched in 'plasma membrane part', 'synapse' and 'integral to plasma membrane' (Table I; Fig. 5A and B); the downregulated DEGs were primarily enriched in 'internal side of plasma membrane', 'lipid particle', and 'plasma membrane part' (Table I; Fig. 5C and D). For molecular function (MF), the upregulated DEGs were primarily enriched in 'transmembrane receptor protein tyrosine kinase activity', 'calcium ion binding' and 'transmembrane receptor protein tyrosine kinase signaling pathway' (Table I; Fig. 5A and B); the downregulated DEGs were primarily enriched in 'GTPase regulator activity', 'nucleoside-triphosphatase regulator activity', and 'calcium ion binding' (Table I; Fig. 5C and D).

According to the KEGG pathway enrichment analysis, upregulated genes were primarily enriched in 'PI3K-Akt signaling pathway', 'ras signaling pathway', 'Rap1 signaling pathway', 'calcium signaling pathway' and 'ErbB signaling pathway' (Table II; Fig. 5E). Downregulated genes were primarily enriched in 'insulin signaling pathway', 'cAMP signaling pathway', 'PPAR signaling pathway', and 'NF-kappa B signaling pathway' (Table II; Fig. 5F).

PPI network construction and modules selection. To investigate the interactions between DEGs, a PPI network for the DEGs was constructed. The PPI network consisted of 338 nodes and 628 edges with a confidence score of $\geq 0.4$ (Fig. 6). A total of 25 hub genes were selected from the PPI network with a degree of $\geq 10$ (Table III), including leucine-rich repeat kinase 2 (LRRK2), phosphatidylinositol-4,5-bisphosphate 3-kinase, catalytic subunit $\gamma$ (PIK3CG), CD44, vascular cell adhesion molecule 1 (VCAM1) and hepatocyte growth factor (HGF). GO enrichment analysis revealed that hub genes were primarily enriched in 'plasma membrane region', 'extracellular exosome', 'angiogenesis', 'regulation of transmembrane transport' and 'protein binding' (Fig. 7A; Table IV). The
KEGG analysis indicated that hub genes were predominantly enriched in 'PI3K-Akt signaling pathway', 'proteoglycans in cancer', 'focal adhesion', 'Rap1 signaling pathway', 'pathways in cancer' and 'ECM-receptor interaction' (Fig. 7B; Table IV).

Four significant modules were screened from the PPI network of DEGs using MCODE plug-in, and enrichment analysis revealed that the module genes in the sub-networks were mainly associated with 'PI3K-Akt signaling pathway', 'Rap1 signaling pathway', 'proteoglycans in cancer' and 'pathways in cancer' (Table IV).

\section{Discussion}

KIT/PDGFRA mutations are the major genetic alterations that occur in the development and progression of GISTs, and have been the only targets of molecular-based therapies in the last decade $(4,30)$. However, other genetic alterations may also be associated with the development and progression of GISTs (15). Currently, little is known about differences in gene expression levels between wild-type GISTs and KIT/PDGFRA mutant GISTs. Therefore, joint bioinformatics analysis was performed in the present study, to obtain other potential candidate biomarkers that may be involved in the development and progression of wild-type GISTs. Ultimately, a total of 546 DEGs were identified, including 238 upregulated DEGs and 308 downregulated DEGs. GO functional and KEGG pathway enrichment analysis of DEGs was subsequently performed. Traditionally, distant metastasis is determined to be the leading cause of morbidity and mortality in patients with cancer, and genes encoding adhesion proteins, inflammatory factors, cytokines, growth factors and transduction molecules are considered major mediators of metastasis $(31,32)$. Enrichment analysis in the present study revealed that the identified DEGs may be involved in the aforementioned process and signaling pathway, and were associated with proliferation, differentiation, apoptosis and distant metastasis in GISTs.

Furthermore, PPI networks of DEGs were constructed and 25 hub genes with degrees of $\geq 10$ were identified. Functional enrichment analysis of hub genes determined that these genes were significantly associated with heterophilic cell-cell adhesion via plasma membrane cell adhesion molecules, regulation of transmembrane transport, cardiovascular system development and angiogenesis. Additionally, pathway analysis indicated that these genes were primarily associated with the following pathways: 'PI3K-Akt signaling pathway', 'proteoglycans in cancer', 'focal adhesion', 'pathways in cancer', 'Rap1 signaling pathway', 'ECM-receptor interaction', 'cell adhesion molecules', 'phospholipase D signaling pathway', 'cAMP signaling pathway', 'Ras signaling pathway' and 'cGMP-PKG signaling pathway'. Furthermore, pathway analyses of four significant modules filtered from the PPI network was performed, and the results revealed that the genes in these modules were also primarily involved in the aforementioned pathways. Specifically, several high-frequency hub genes were identified that may be involved in the progression of GISTs by combining these results, including PIK3CG, insulin like growth factor 1 receptor (IGF1R), HGF, thrombospondin 1 (THBS1), Erb-B2 receptor tyrosine kinase (ERBB) 2 and matrix metallopeptidase 2 (MMP2). 
Density plot of first batch

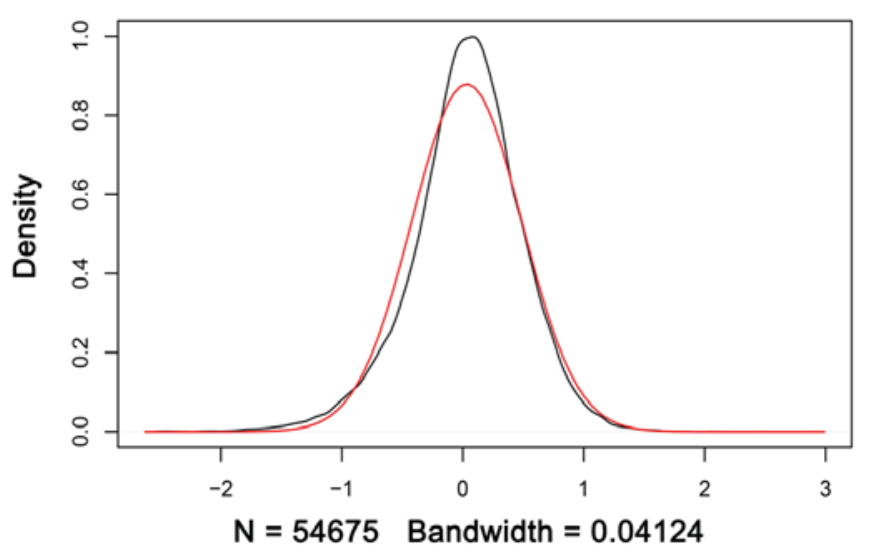

Density plot of first batch

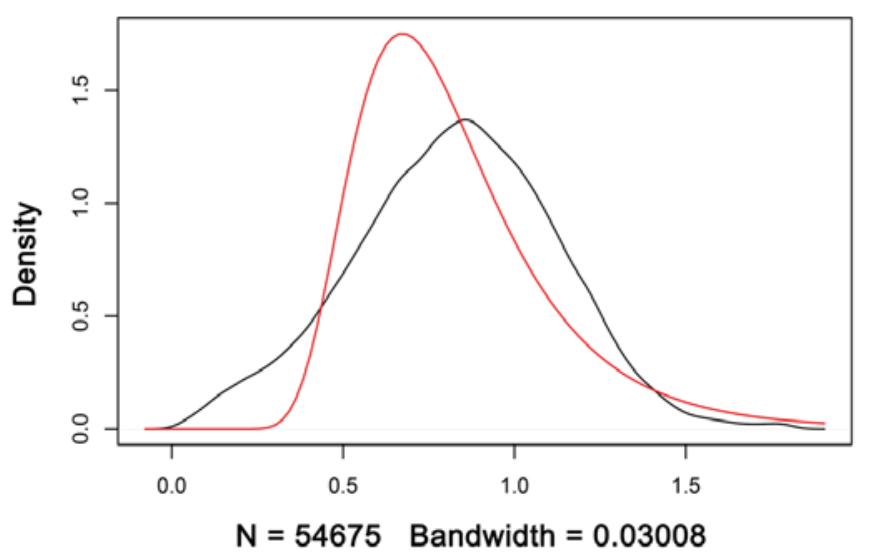

Normal Q-Q plot of first batch

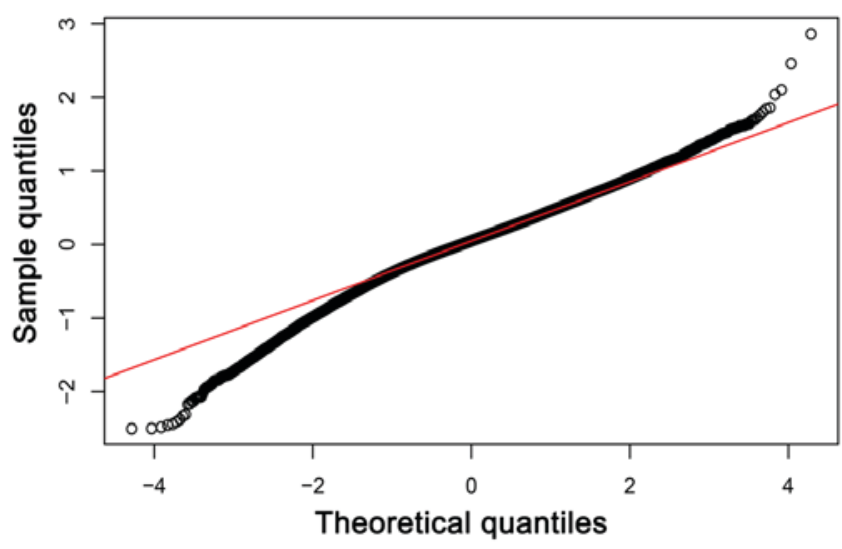

Inverse gamma $Q-Q$ plot of first batch

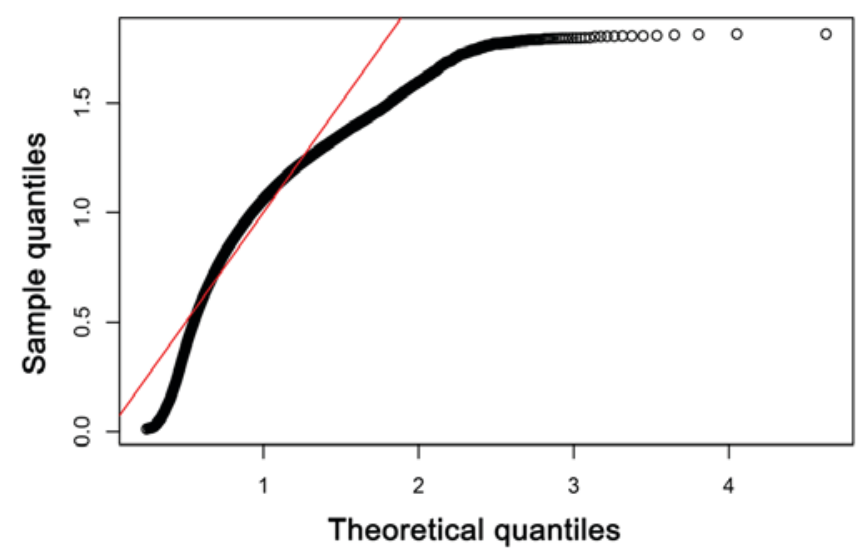

Figure 1. Batch effect plots between the two gene expression profile datasets.

A

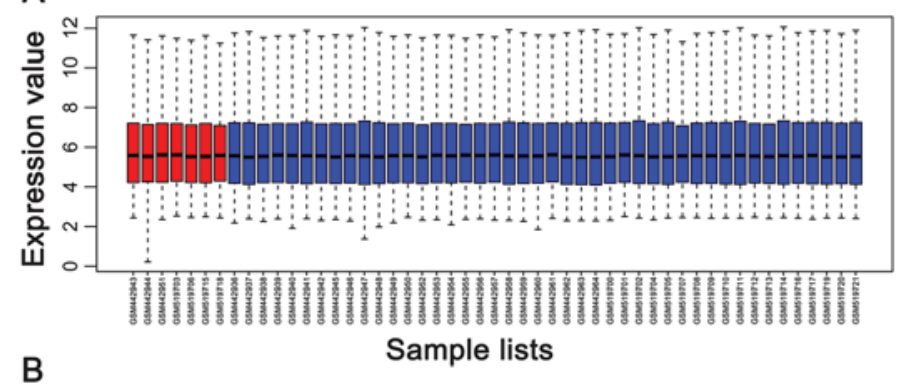

B

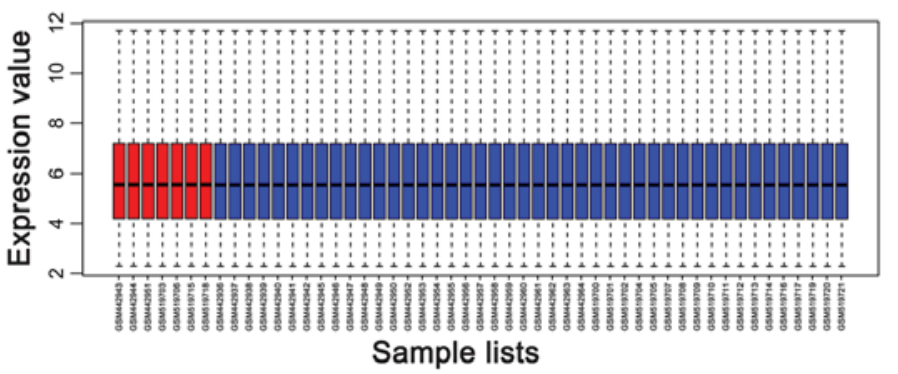

C

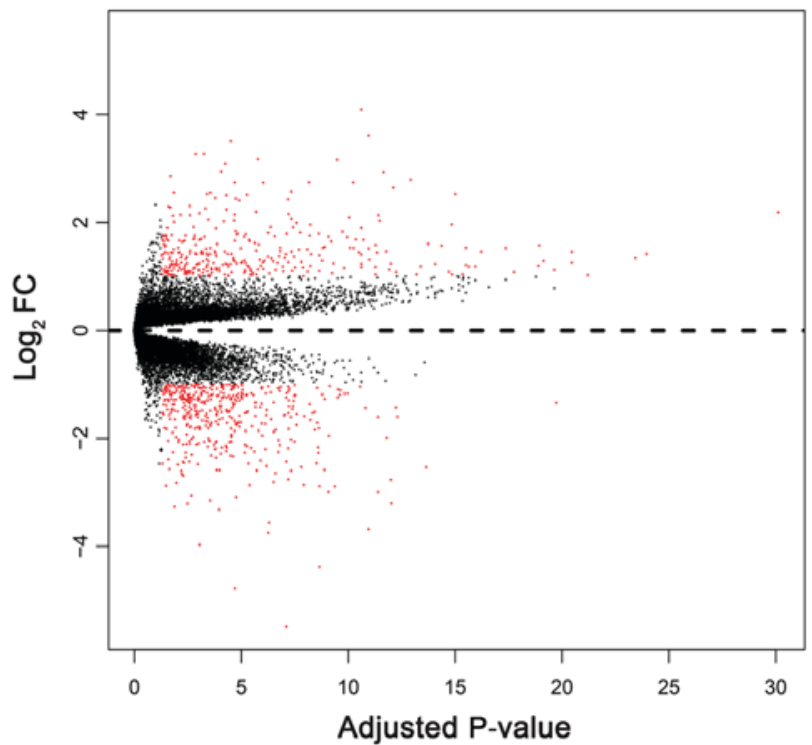

Figure 2. Box plots of gene expression profiles of GIST samples and the distribution of DEGs. (A) Gene expression profile of each sample prior to data normalization. (B) Gene expression profile of each sample following data normalization. (C) Volcano plot of gene distribution in wild-type GIST samples compared with KIT/PDGFRA mutant GIST samples. In (A) and (B), the horizontal axis and vertical axis represent samples and gene expression values, respectively; the red boxes and the blue boxes represent the wild-type GIST samples and the KIT/PDGFRA mutant GIST samples, respectively. In (C), the red plot represents statistically significant DEGs (FC $\geq 1$ and $\mathrm{P}<0.05)$. The black plot represents genes with no significant expression changes. DEGs, differentially expressed genes; GISTs, gastrointestinal stromal tumors; FC, fold change; KIT, v-kit Hardy-Zuckerman 4 feline sarcoma viral oncogene homolog; PDGFRA, platelet-derived growth factor receptor $\alpha$. 

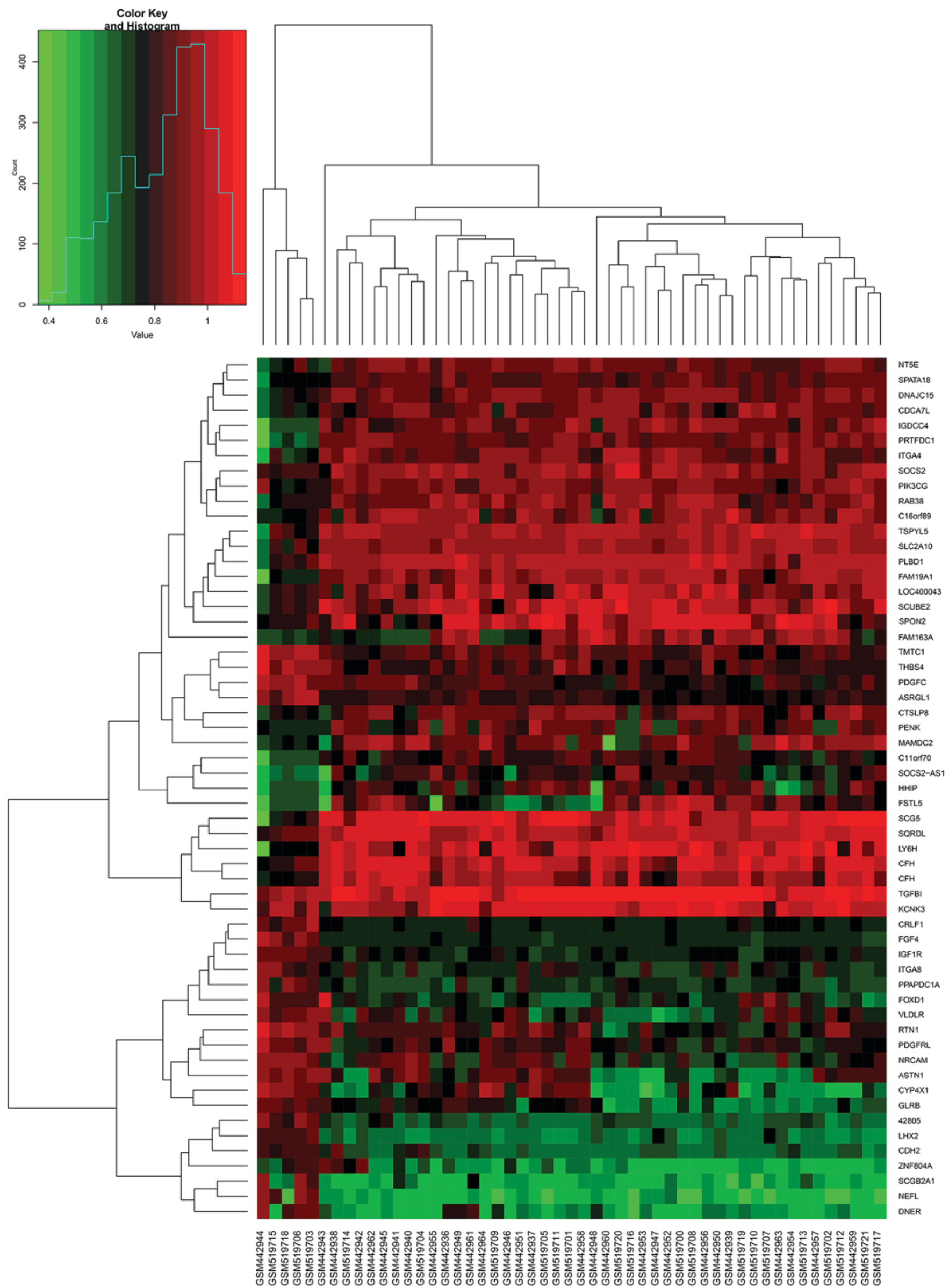

Figure 3. Hierarchical clustering heatmap of fractional DEGs. The horizontal axis indicates the sample, and the vertical axis indicates the DEGs. Red represents the upregulated DEGs and green represents the downregulated DEGs. DEGs, differentially expressed genes. 


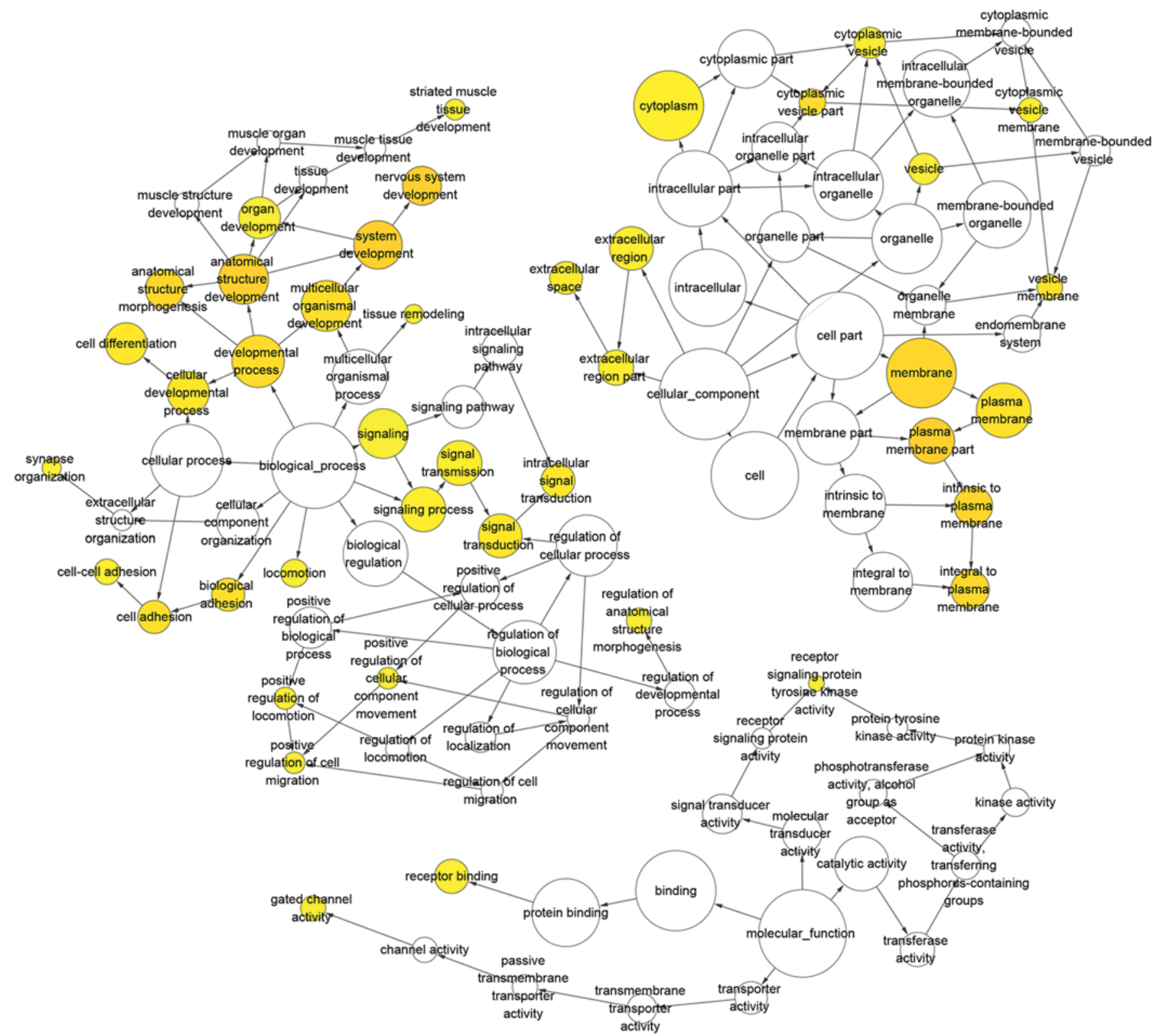

Figure 4. Directed acyclic graph of GO enrichment analysis and DEG functional annotation. Circles represent GO function, the upstream GO function includes the downstream GO function (arrows) and the color intensity represents the degree of GO function enrichment. DEGs, differentially expressed genes; GO, gene ontology.

The PIK3CG gene is located on chromosome 7 long arm q22.3, contains 12 exons, and encodes phosphoinositide 3-kinase (PI3K) $\gamma$, which phosphorylates inositol lipids and is involved in the immune response (33). Semba et al (34) reported that the PIK3CG gene is downregulated in colorectal cancer and is involved in tumorigenesis and progression, mainly through the PI3K-protein kinase B (Akt) signaling pathway. Li et al (35) determined that the PI3K-Akt signaling pathway is partially activated following imatinib secondary resistance, and PI3K activation may occur at an early stage of secondary resistance. In the present study, PIK3CG was downregulated in wild-type GISTs. PIK3CG was identified as a hub gene with 29 degrees in the PPI network, and as the core gene of module 2 . The enrichment analyses demonstrated that PIK3CG was associated with cardiovascular and vasculature development, regulation of transmembrane transport, angiogenesis and anatomical structure morphogenesis, as well as the PI3K-Akt signaling pathway, phospholipase D signaling pathway and cAMP signaling pathway. This suggested that PIK3CG may be a key molecule associated with wild-type GISTs.

IGF1R, a transmembrane receptor tyrosine kinase, serves a critical role in tumor transformation and malignant cell survival. IGF1R is predominantly involved in two signaling pathways: The PI3K-Akt pathway and the Ras-mitogen-activated protein kinase pathway (36). Ludovini et al (37) identified that activation of IGF1R is a necessary condition for mediating tumor cell proliferation and invasion, and is an independent poor prognostic factor in early stage non-small cell lung cancer. In addition, previous studies have demonstrated that IGF1R is overexpressed in wild-type GISTs, and inhibition of IGF1R signaling may be an effective therapeutic strategy (38-41). In 
Table I. GO enrichment analysis and functional annotation of DEGs.

A, Upregulated

\begin{tabular}{|c|c|c|c|c|c|}
\hline Category & Term & Description & Count & $\%$ & P-value \\
\hline GOTERM_BP_FAT & GO:0007155 & Cell adhesion & 25 & 11.1 & $7.08 \times 10^{-6}$ \\
\hline GOTERM_BP_FAT & GO:0022610 & Biological adhesion & 25 & 11.1 & $7.26 \times 10^{-6}$ \\
\hline GOTERM_BP_FAT & GO:0050808 & Synapse organization & 7 & 3.1 & $1.13 \times 10^{-4}$ \\
\hline GOTERM_BP_FAT & GO:0007169 & $\begin{array}{l}\text { Transmembrane receptor protein tyrosine } \\
\text { kinase signaling pathway }\end{array}$ & 12 & 5.3 & $1.24 \times 10^{-4}$ \\
\hline GOTERM_BP_FAT & GO:0007267 & Cell-cell signaling & 19 & 8.4 & $5.50 \times 10^{-4}$ \\
\hline GOTERM_CC_FAT & GO:0044459 & Plasma membrane part & 55 & 24.4 & $7.52 \times 10^{-6}$ \\
\hline GOTERM_CC_FAT & GO:0045202 & Synapse & 18 & 8.0 & $8.07 \times 10^{-6}$ \\
\hline GOTERM_CC_FAT & GO:0005887 & Integral to plasma membrane & 35 & 15.6 & $2.90 \times 10^{-5}$ \\
\hline GOTERM_CC_FAT & GO:0030054 & Cell junction & 21 & 9.3 & $3.00 \times 10^{-5}$ \\
\hline GOTERM_CC_FAT & GO:0031226 & Intrinsic to plasma membrane & 35 & 15.6 & $4.59 \times 10^{-5}$ \\
\hline GOTERM_MF_FAT & GO:0004714 & $\begin{array}{l}\text { Transmembrane receptor protein tyrosine } \\
\text { kinase activity }\end{array}$ & 6 & 2.7 & $1.36 \times 10^{-3}$ \\
\hline GOTERM_MF_FAT & GO:0005509 & Calcium ion binding & 22 & 9.8 & $4.10 \times 10^{-3}$ \\
\hline GOTERM_MF_FAT & GO:0022843 & Voltage-gated cation channel activity & 7 & 3.1 & $9.44 \times 10^{-3}$ \\
\hline GOTERM_MF_FAT & GO:0022836 & Gated channel activity & 10 & 4.4 & $1.41 \times 10^{-2}$ \\
\hline GOTERM_MF_FAT & GO:0008083 & Growth factor activity & 7 & 3.1 & $1.43 \times 10^{-2}$ \\
\hline
\end{tabular}

B, Downregulated

\begin{tabular}{|c|c|c|c|c|c|}
\hline GOTERM_BP_FAT & GO:0016125 & Sterol metabolic process & 6 & 2.2 & $1.22 \times 10^{-2}$ \\
\hline GOTERM_BP_FAT & GO:0006954 & Inflammatory response & 11 & 4.1 & $1.34 \times 10^{-2}$ \\
\hline GOTERM_BP_FAT & GO:0007229 & Integrin-mediated signaling pathway & 5 & 1.9 & $1.51 \times 10^{-2}$ \\
\hline GOTERM_BP_FAT & GO:0006631 & Fatty acid metabolic process & 8 & 3.0 & $1.87 \times 10^{-2}$ \\
\hline GOTERM_BP_FAT & GO:0007264 & Small GTPase mediated signal transduction & 10 & 3.7 & $2.38 \times 10^{-2}$ \\
\hline GOTERM_CC_FAT & GO:0009898 & Internal side of plasma membrane & 12 & 4.5 & $4.55 \times 10^{-2}$ \\
\hline GOTERM_CC_FAT & GO:0005811 & Lipid particle & 3 & 1.1 & $1.78 \times 10^{-2}$ \\
\hline GOTERM_CC_FAT & GO:0044459 & Plasma membrane part & 42 & 15.7 & $2.57 \times 10^{-2}$ \\
\hline GOTERM_CC_FAT & GO:0005739 & Mitochondrion & 24 & 9.0 & $2.68 \times 10^{-2}$ \\
\hline GOTERM_CC_FAT & GO:0031090 & Organelle membrane & 24 & 9.0 & $2.91 \times 10^{-2}$ \\
\hline GOTERM_MF_FAT & GO:0030695 & GTPase regulator activity & 14 & 5.2 & $3.60 \times 10^{-3}$ \\
\hline GOTERM_MF_FAT & GO:0060589 & Nucleoside-triphosphatase regulator activity & 14 & 5.2 & $4.34 \times 10^{-3}$ \\
\hline GOTERM_MF_FAT & GO:0005509 & Calcium ion binding & 23 & 8.6 & $6.95 \times 10^{-3}$ \\
\hline GOTERM_MF_FAT & GO:0005178 & Integrin binding & 5 & 1.9 & $8.49 \times 10^{-3}$ \\
\hline GOTERM_MF_FAT & GO:0005096 & GTPase activator activity & 8 & 3.0 & $3.12 \times 10^{-2}$ \\
\hline
\end{tabular}

Count indicates the enriched gene number in the category. GO, gene ontology; DEGs, differentially expressed genes BP, biological process; $\mathrm{CC}$, cellular component; MF, molecular function.

the present study, IGF1R was upregulated in wild-type GIST samples and was associated with fibroblast growth factor receptor (FGFR) 4, Janus kinase 3 and tyrosine-protein kinase SYK in module 1. Pathway analysis revealed that IGF1R was associated with the PI3K-Akt signaling pathway, proteoglycans in cancer, and ras signaling pathway. These findings were consistent with the results of the aforementioned studies and indicated that IGF1R overexpression may act as an alternative genetic alteration event to the KIT/PDGFRA mutations in GISTs. Therefore, further research is necessary to clarify underlying mechanisms of IGF1R in wild-type GISTs.
HGF, also known as scatter factor, is a member of the endothelium-specific growth factor family, and regulates cell growth and motility, migration, and angiogenesis through binding to its receptor c-Met (42). Hack et al (43) revealed that aberrant activation of the HGF/MET signaling pathway occurs in the malignant transformation and progression of gastroesophageal cancer, and consistently correlates with an aggressive metastatic phenotype and poor prognosis. However, there is a lack of research on the role of HGF in GISTs. The results of enrichment analysis in the present study demonstrated that HGF was associated with angiogenesis, 
Table II. KEGG pathways analysis results of DEGs.

A, Upregulated

\begin{tabular}{|c|c|c|c|c|}
\hline Pathway ID & Description & Count & P-value & Genes \\
\hline hsa05218 & Melanoma & 7 & $4.22 \times 10^{-7}$ & CDK6, HGF, FGF3, FGF10, IGF1R, FGF4, PDGFC \\
\hline hsa04151 & PI3K-Akt signaling pathway & 12 & $1.53 \times 10^{-6}$ & $\begin{array}{l}\text { CDK6, HGF, FGF3, MYB, EFNA2, FGF10, IGF1R, } \\
\text { FGF4, ITGA8, PPP2R2B, PDGFC, THBS4 }\end{array}$ \\
\hline hsa04514 & Cell adhesion molecules (CAMs) & 8 & $4.06 \times 10^{-6}$ & $\begin{array}{l}\text { PVRL3, NRXN1, CDH2, NRCAM, CNTNAP2, } \\
\text { ITGA8, NLGN4X, CADM1 }\end{array}$ \\
\hline hsa04014 & Ras signaling pathway & 9 & $1.30 \times 10^{-5}$ & $\begin{array}{l}\text { HGF, SHC3, FGF3, EFNA2, FGF10, IGF1R, HTR7, } \\
\text { FGF4, PDGFC }\end{array}$ \\
\hline hsa01521 & $\begin{array}{l}\text { EGFR tyrosine kinase inhibitor } \\
\text { resistance }\end{array}$ & 6 & $1.34 \times 10^{-5}$ & HGF, SHC3, ERBB3, ERBB2, IGF1R, PDGFC \\
\hline hsa04512 & ECM-receptor interaction & 6 & $1.43 \times 10^{-5}$ & CD44, SV2B, CD36, ITGA8, THBS4, SV2C \\
\hline hsa04510 & Focal adhesion & 8 & $3.98 \times 10^{-5}$ & $\begin{array}{l}\text { ARHGAP5, HGF, SHC3, ERBB2, IGF1R, ITGA8, } \\
\text { PDGFC, THBS4 }\end{array}$ \\
\hline hsa04015 & Rap1 signaling pathway & 8 & $5.17 \times 10^{-5}$ & $\begin{array}{l}\text { HGF, FGF3, EFNA2, FGF10, IGF1R, FGF4, ADCY2, } \\
\text { PDGFC }\end{array}$ \\
\hline hsa04020 & Calcium signaling pathway & 7 & $1.31 \times 10^{-4}$ & $\begin{array}{l}\text { ATP2B1, ERBB3, ERBB2, HTR7, TACR1, CAMK4, } \\
\text { ADCY2 }\end{array}$ \\
\hline hsa05200 & Pathways in cancer & 10 & $1.70 \times 10^{-4}$ & $\begin{array}{l}\text { CDK6, HGF, DAPK1, ERBB2, FGF3, FGF10, IGF1R, } \\
\text { FZD2, FGF4, ADCY2 }\end{array}$ \\
\hline hsa05014 & Amyotrophic lateral sclerosis (ALS) & 4 & $3.18 \times 10^{-4}$ & GRIA2, MAP3K5, GRIA1, NEFL \\
\hline hsa04080 & $\begin{array}{l}\text { Neuroactive ligand-receptor } \\
\text { interaction }\end{array}$ & 8 & $3.22 \times 10^{-4}$ & $\begin{array}{l}\text { GRIA2, PRLHR, PTH1R, HTR7, TACR1, GRIA1, } \\
\text { OPRK1, GLRB }\end{array}$ \\
\hline hsa04730 & Long-term depression & 4 & $5.69 \times 10^{-4}$ & GRIA2, IGF1R, GRIA1, PPP1R17 \\
\hline hsa05205 & Proteoglycans in cancer & 6 & $1.66 \times 10^{-3}$ & HGF, CD44, ERBB3, ERBB2, IGF1R, FZD2 \\
\hline hsa04012 & ErbB signaling pathway & 4 & $2.20 \times 10^{-3}$ & SHC3, ERBB3, ERBB2, NRG3 \\
\hline
\end{tabular}

B, Downregulated

\begin{tabular}{|c|c|c|c|c|}
\hline Pathway ID & Description & Count & P-value & Genes \\
\hline hsa05145 & Toxoplasmosis & 7 & $5.50 \times 10^{-5}$ & $\begin{array}{l}\text { PIK3CG, SOCS1, HLA-DPA1, MYD } 88, \text { CD } 40, \\
\text { LDLR, MAPK10 }\end{array}$ \\
\hline hsa04925 & Aldosterone synthesis and secretion & 6 & $5.68 \times 10^{-5}$ & $\begin{array}{l}\text { KCNK3, PDE2A, CREB3L1, LDLR, ORAI1, } \\
\text { CACNA1H }\end{array}$ \\
\hline hsa05144 & Malaria & 5 & $5.85 \times 10^{-5}$ & VCAM1, THBS1, GYPC, MYD88, CD40 \\
\hline hsa04810 & Regulation of actin cytoskeleton & 9 & $6.24 \times 10^{-5}$ & $\begin{array}{l}\text { ITGA4, PIK3CG, CD14, F2R, FGFR4, MRAS, SSH3, } \\
\text { VAV2, ITGAE }\end{array}$ \\
\hline hsa04910 & Insulin signaling pathway & 7 & $1.39 \times 10^{-4}$ & $\begin{array}{l}\text { PIK3CG, SOCS2, SOCS1, SREBF1, PYGM, PDE3B, } \\
\text { MAPK10 }\end{array}$ \\
\hline hsa04024 & cAMP signaling pathway & 8 & $2.08 \times 10^{-4}$ & $\begin{array}{l}\text { HHIP, PIK3CG, F2R, CREB3L1, PDE3B, ORAI1, } \\
\text { MAPK10, VAV2 }\end{array}$ \\
\hline hsa05205 & Proteoglycans in cancer & 8 & $2.52 \times 10^{-4}$ & $\begin{array}{l}\text { MMP2, CTSL, PIK3CG, THBS1, WNT5B, WNT9A, } \\
\text { MRAS, VAV2 }\end{array}$ \\
\hline hsa04931 & Insulin resistance & 6 & $2.65 \times 10^{-4}$ & $\begin{array}{l}\text { PIK3CG, CREB3L1, SREBF1, PYGM, CPT1A, } \\
\text { MAPK10 }\end{array}$ \\
\hline hsa03320 & PPAR signaling pathway & 5 & $3.17 \times 10^{-4}$ & ME1, PLIN2, CPT1A, ACSL5, CYP27A1 \\
\hline hsa00071 & Fatty acid degradation & 4 & $4.98 \times 10^{-4}$ & ACAA2, CPT1A, ACSL5, ALDH7A1 \\
\hline hsa01212 & Fatty acid metabolism & 4 & $6.77 \times 10^{-4}$ & PTPLAD2, ACAA2, CPT1A, ACSL5 \\
\hline hsa04930 & Type II diabetes mellitus & 4 & $6.77 \times 10^{-4}$ & PIK3CG, SOCS2, SOCS1, MAPK10 \\
\hline hsa04064 & NF-kappa B signaling pathway & 5 & $9.57 \times 10^{-4}$ & VCAM1, CD14, SYK, MYD88, CD40 \\
\hline hsa05166 & HTLV-I infection & 8 & $1.11 \times 10^{-3}$ & $\begin{array}{l}\text { JAK3, PIK3CG, VCAM1, WNT5B, HLA-DPA1, } \\
\text { WNT9A, MRAS, CD40 }\end{array}$ \\
\hline
\end{tabular}


Table II. Continued.

B, Downregulated

\begin{tabular}{lcccc}
\hline Pathway ID & Description & Count & P-value & Genes \\
\hline hsa04510 & Focal adhesion & 7 & $1.22 \times 10^{-3}$ & ITGA4, PIK3CG, THBS1, PARVA, MAPK10, VAV2, PARVB \\
\hline
\end{tabular}

Count indicates the enriched gene number in the pathway. KEGG, Kyoto Encyclopedia of Genes and Genomes; DEGs, differentially expressed genes.

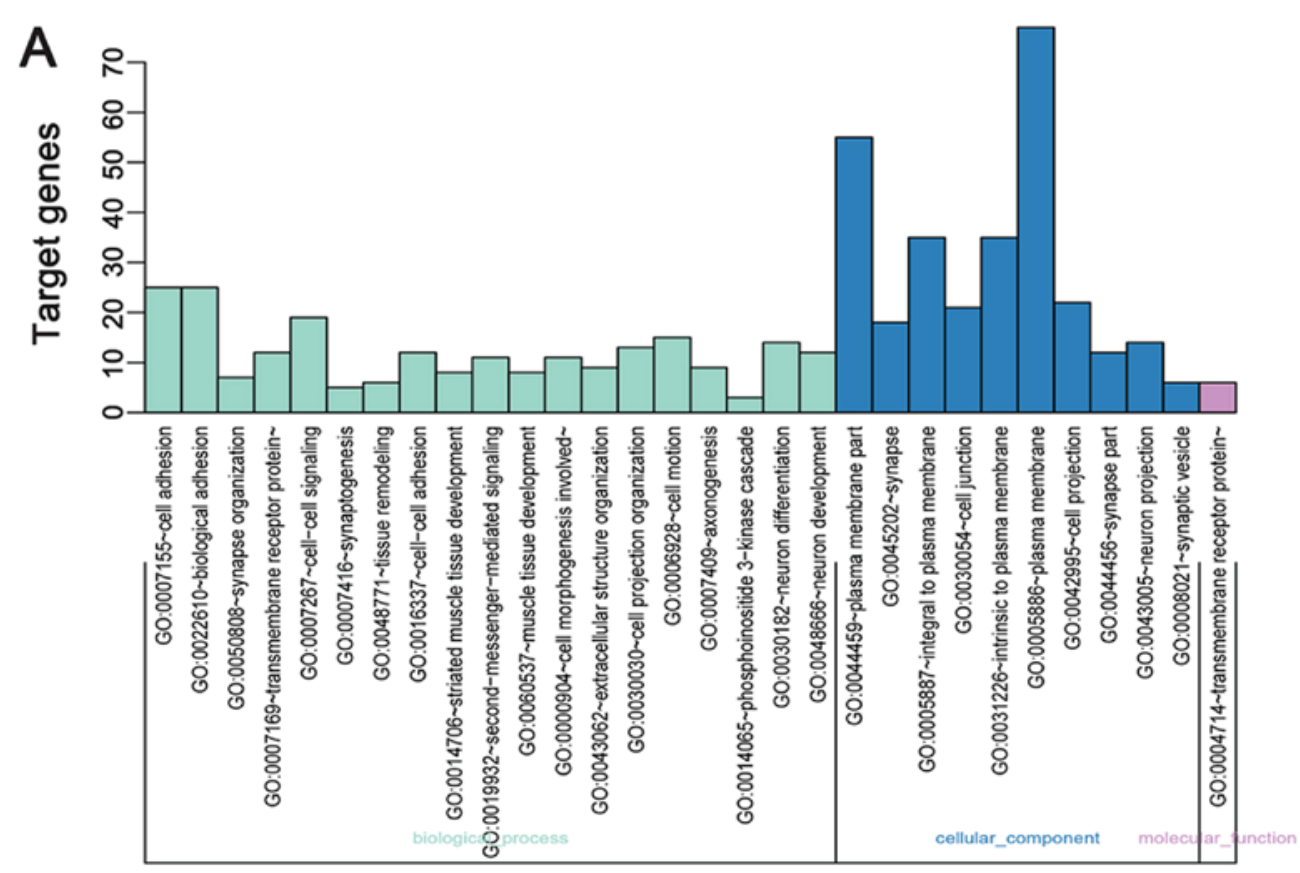

\section{Upregulated GO terms}

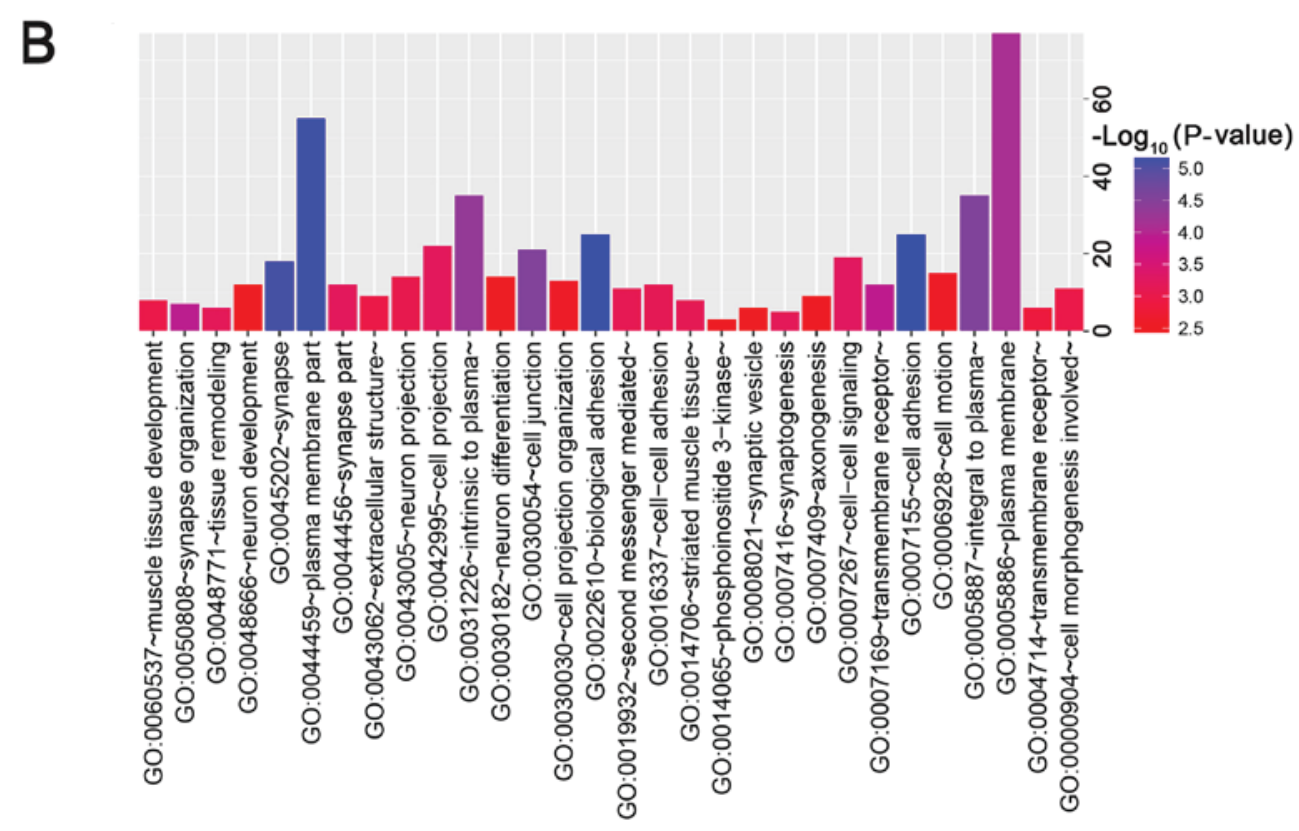

\section{Upregulated GO terms}

Figure 5. GO functional and KEGG pathway enrichment analysis of DEGs. (A) GO functional enrichment analysis of upregulated DEGs based on the three types of sub-ontologies and (B) P-value. 


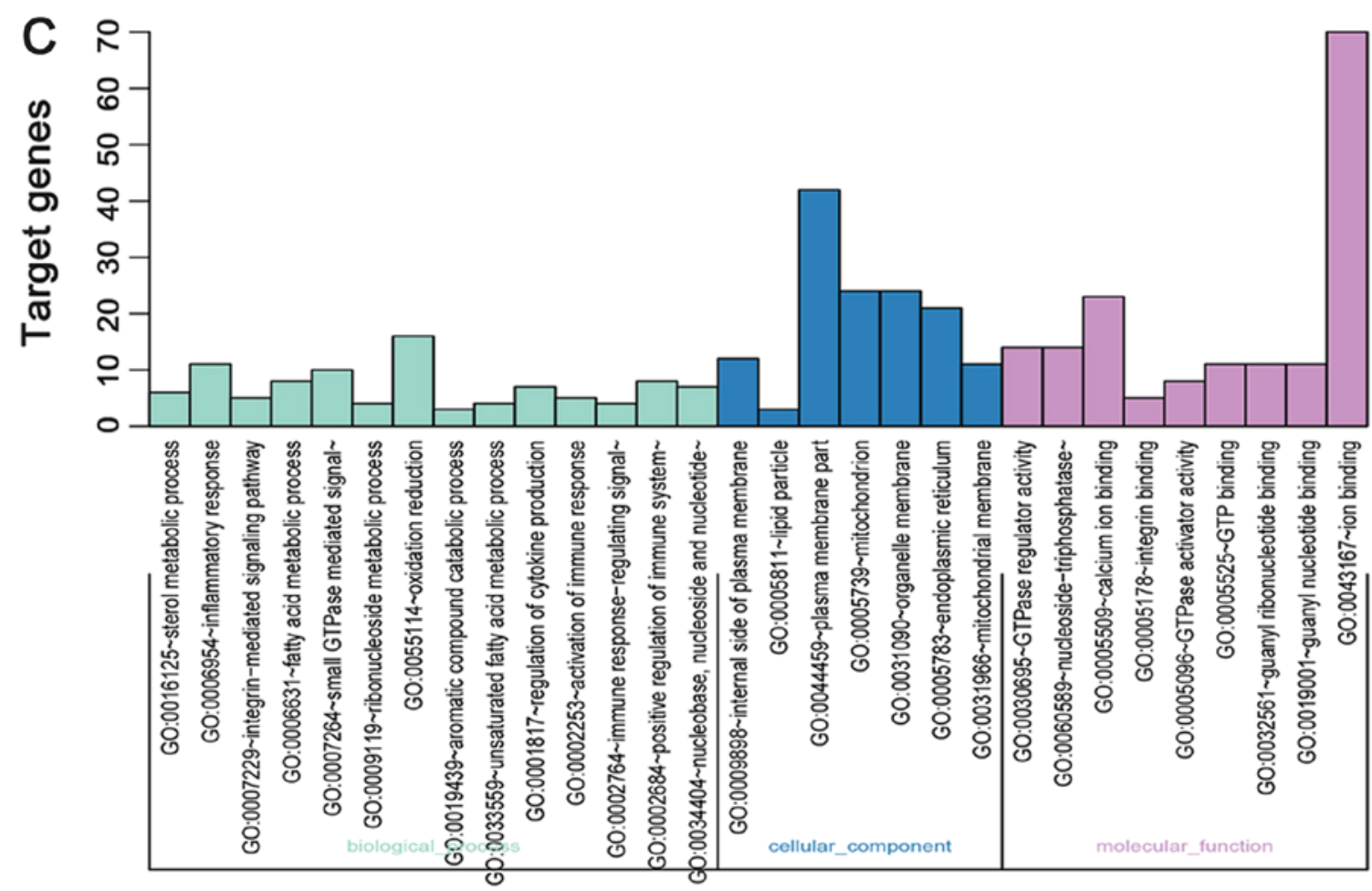

\section{Downregulated GO terms}

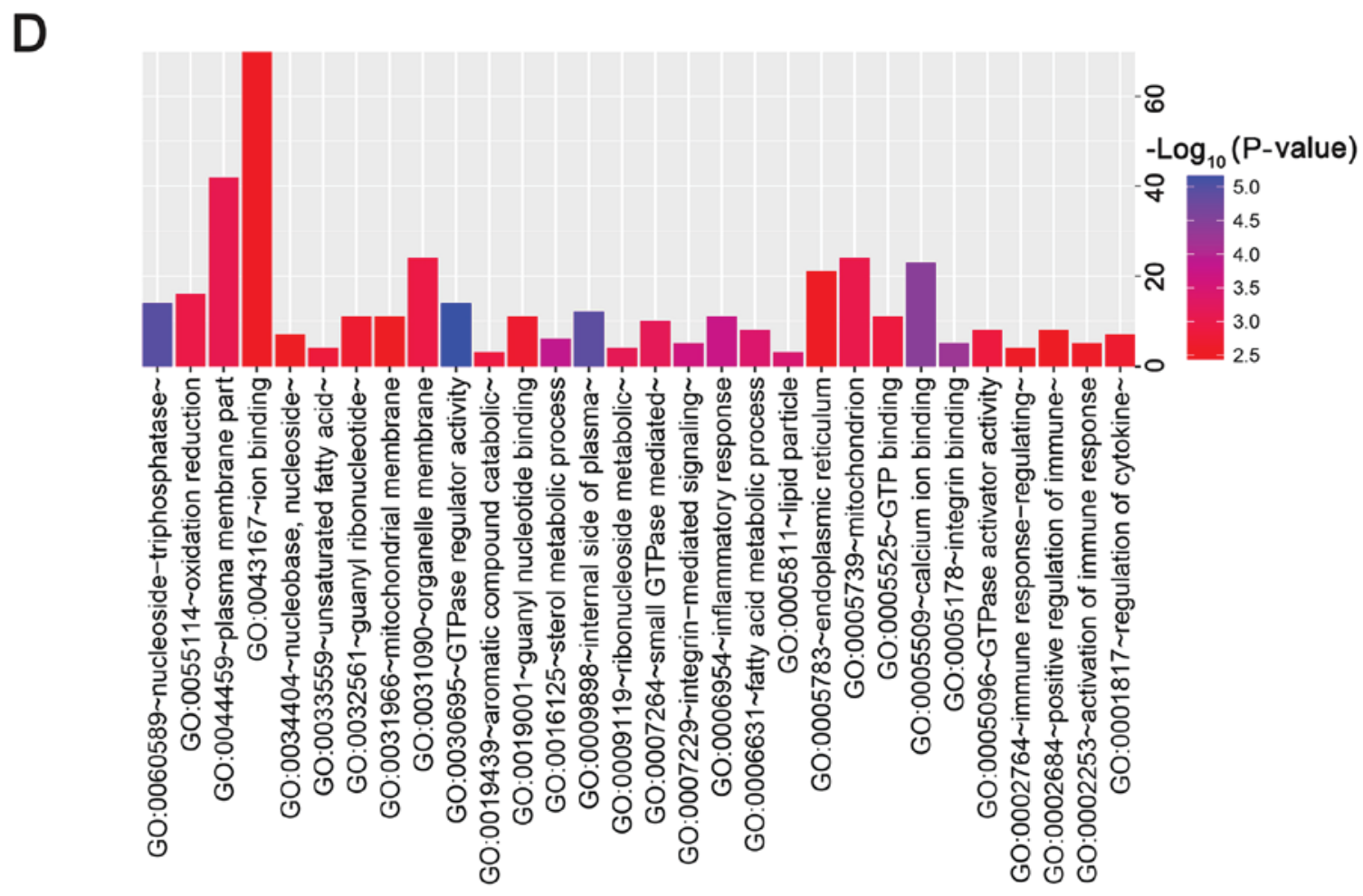

Downregulated GO terms

Figure 5. Continued. (C) GO functional enrichment analysis of downregulated DEGs (top 30 terms) based on the three types of sub-ontologies and (D) P-value. The horizontal axis and vertical axis indicate the names of GO terms and the number of target genes, respectively.

cardiovascular and vasculature development, proteoglycans in cancer, focal adhesion, pathways in cancer, and PI3K-Akt signaling pathway. Furthermore, it was associated with Wnt family member (WNT) 5B, ERBB3, and WNT9A in module 4, revealing that HGF may be involved in progression of wild-type GISTs.

THBS1, also known as TSP-1, encodes an adhesive glycoprotein that is involved in platelet aggregation, angiogenesis 


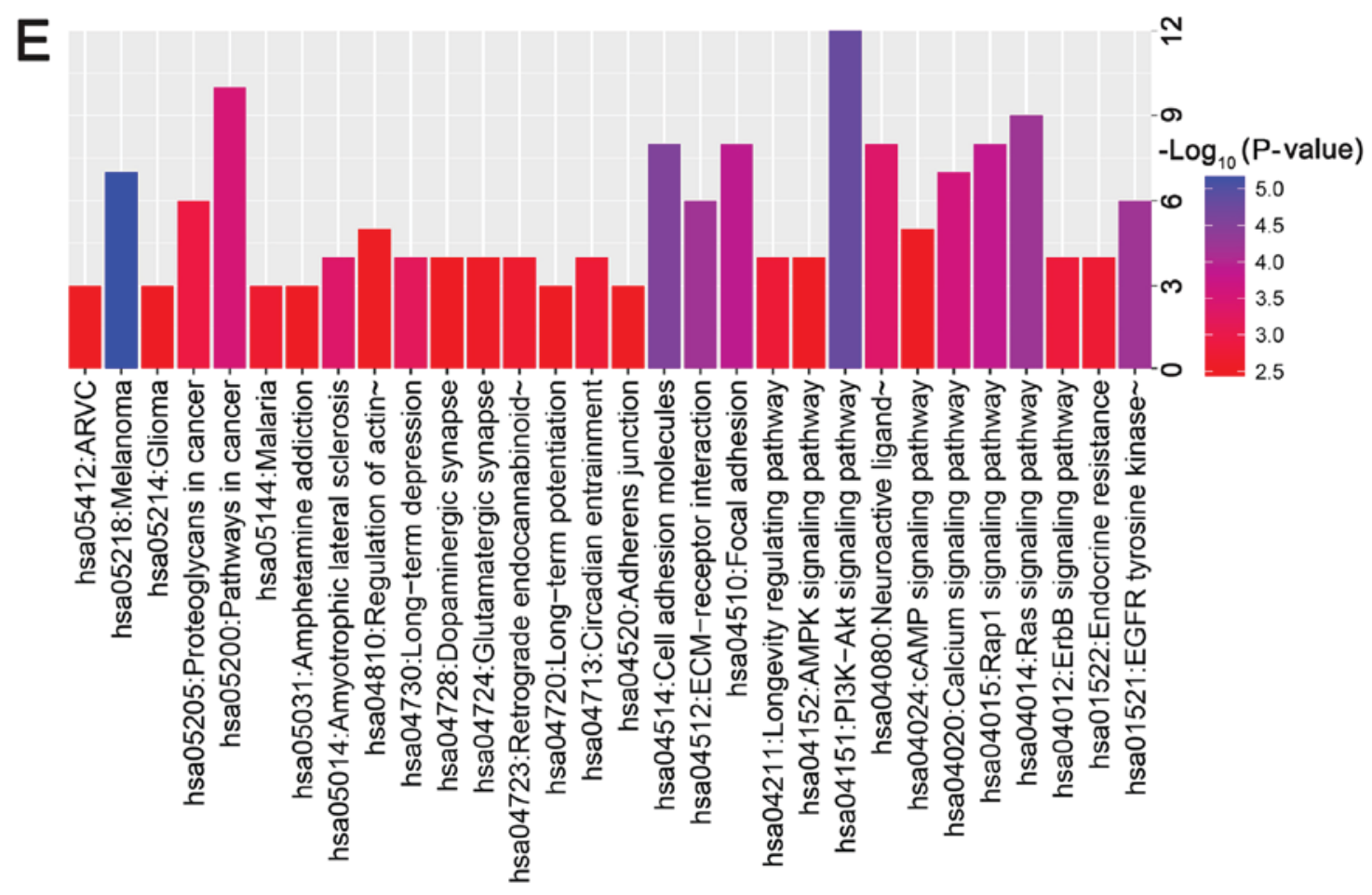

\section{Upregulated KEGG terms}

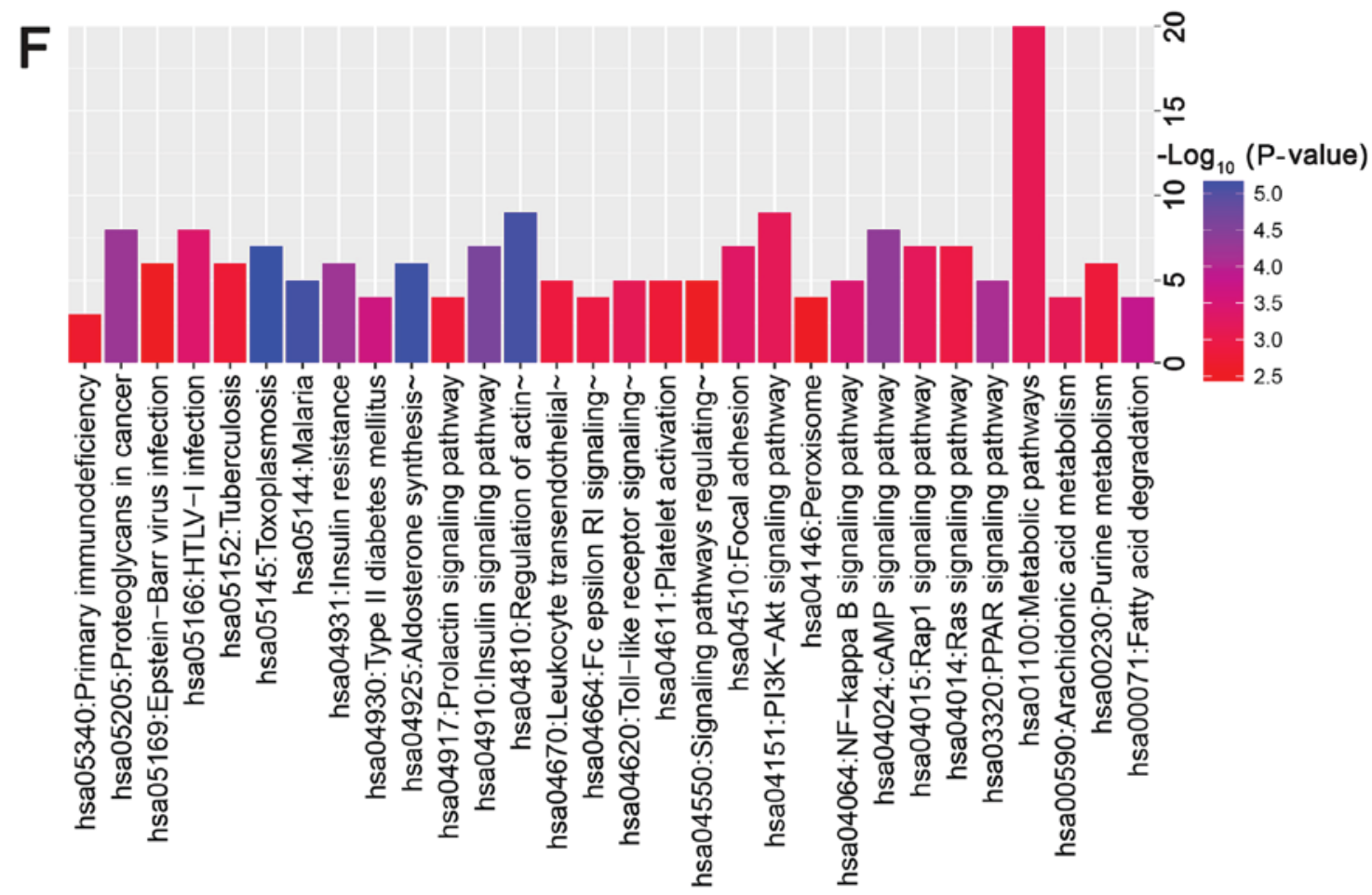

\section{Downregulated KEGG terms}

Figure 5. Continued. KEGG functional enrichment analysis of (E) upregulated and (F) downregulated DEGs (top 30 terms) are presented, based on P-value. The color of the pillars represents the size of the P-value, with the red color representing the smallest P-value. DEGs, differentially expressed genes; GO, gene ontology; KEGG, Kyoto Encyclopedia of Genes and Genomes.

and tumorigenesis (44). In the present study, THBS1 was associated with proteoglycans in cancer, ECM-receptor interaction, PI3K-Akt signaling pathway, and rap1 signaling pathway. In addition, functional enrichment analysis 


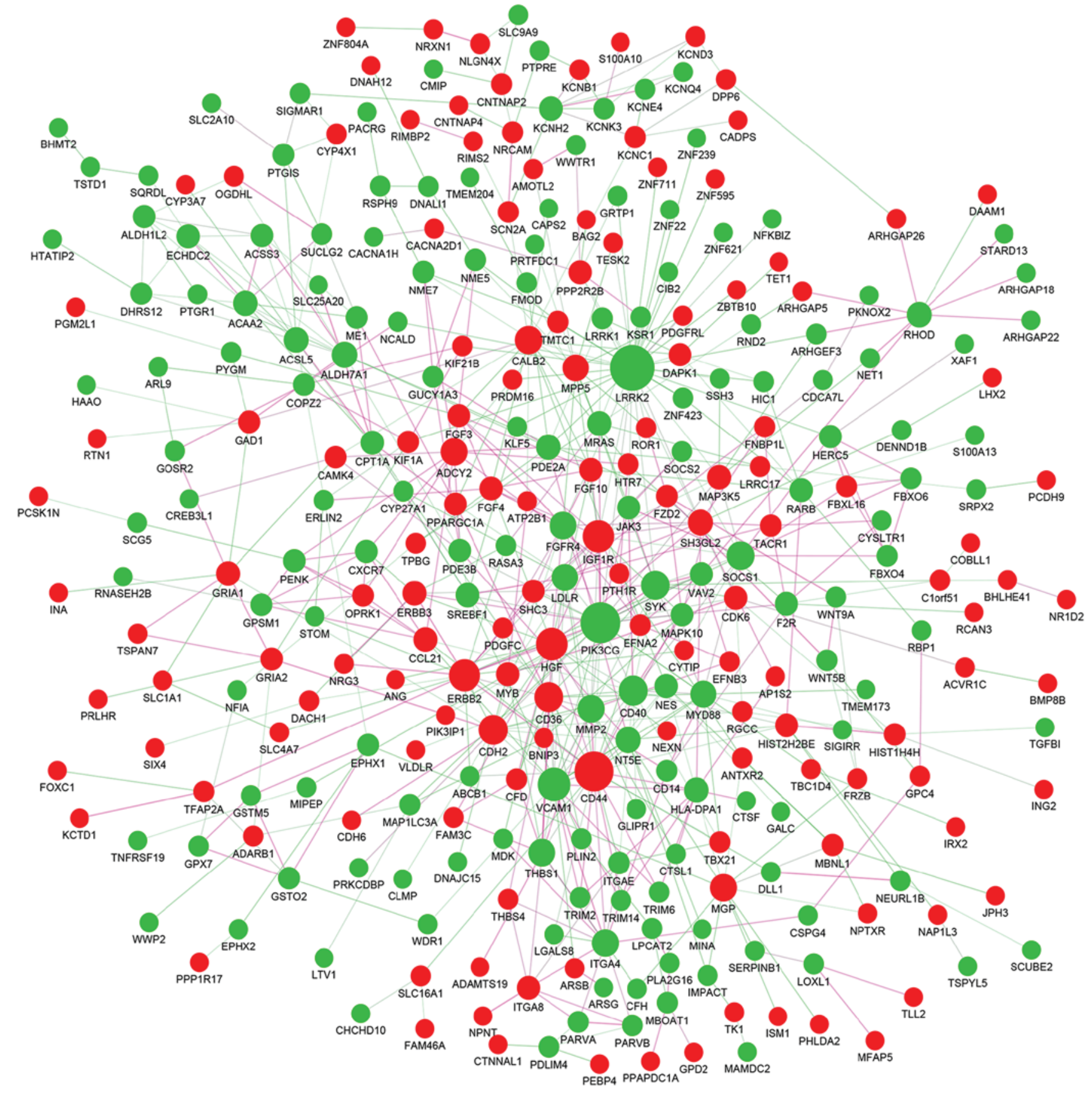

Figure 6. Protein-protein interaction network of identified differentially expressed genes. Red nodes represent the upregulated genes, while green nodes represent the downregulated genes. The magnitude of each node represents the extent to which each gene is linked, and the lines represent the interaction relationship between nodes.

identified that THBS1 was associated with angiogenesis, protein binding, cell adhesion, regulation of transmembrane transport and inflammatory response. Kashihara et al (45) revealed that THBS1 is associated with carcinogenesis occurring in patients with intestinal inflammation, and may serve an important role in gastric carcinogenesis. Huang et al (46) reported that upregulation of THBS1 is induced by FGF7/FGFR2 via the PI3K/Akt/mechanistic target of rapamycin signaling pathway, and is associated with the regulation of invasion and migration in gastric cancer. However, no studies have elucidated the mechanism of THBS1 in GISTs. In module 3, THBS1 was associated with adenyl cyclase type 2 (ADCY2), FGF10, FGF3, FGF4, CD36 and CD44, indicating that THBS1 may also be involved in GISTs by mediating these genes. Therefore, further research is necessary to clarify the underlying mechanism of THBS1 in wild-type GISTs.

ERBB2, also known as Her2 or Neu, is a member of the ERBB family of receptor tyrosine kinases. It encodes a transmembrane tyrosine kinase receptor of the ERBB family that has important roles in many aspects of various human cancers $(47,48)$. However, the oncogenic role and clinical significance of ERBB2 in GISTs has not been investigated in detail. In the present study, ERBB2 was upregulated and 
Table III. Top 25 hub genes identified in PPI network of DEGs.

\begin{tabular}{|c|c|c|c|c|c|c|}
\hline Affy ID & Gene symbol & Gene name & Degree & $\log \mathrm{FC}$ & P-value & Regulation \\
\hline 229584_at & LRRK2 & Leucine rich repeat kinase 2 & 36 & -1.78 & $1.04 \times 10^{-4}$ & Down \\
\hline 206369_s_at & PIK3CG & $\begin{array}{l}\text { Phosphatidylinositol-4,5-bisphosphate 3-kinase, } \\
\text { catalytic subunit gamma }\end{array}$ & 29 & -1.89 & $5.37 \times 10^{-6}$ & Down \\
\hline 204489_s_at & CD44 & CD44 molecule (Indian blood group) & 28 & 1.11 & $1.14 \times 10^{-3}$ & Up \\
\hline 203868_s_at & VCAM1 & Vascular cell adhesion molecule 1 & 20 & -1.76 & $8.36 \times 10^{-4}$ & Down \\
\hline 209960_at & HGF & Hepatocyte growth factor & 19 & 1.05 & $2.25 \times 10^{-3}$ & Up \\
\hline 216836_s_at & ERBB2 & Erb-b2 receptor tyrosine kinase 2 & 18 & 1.21 & $6.69 \times 10^{-5}$ & Up \\
\hline 243358_at & IGF1R & Insulin-like growth factor 1 receptor & 18 & 1.39 & $1.72 \times 10^{-11}$ & Up \\
\hline 203441_s_at & $\mathrm{CDH} 2$ & Cadherin 2 & 15 & 1.41 & $2.63 \times 10^{-8}$ & $\mathrm{Up}$ \\
\hline 206488_s_at & CD36 & CD36 molecule & 15 & 1.49 & $2.97 \times 10^{-3}$ & Up \\
\hline 205153_s_at & CD40 & CD40 molecule & 15 & -1.12 & $5.87 \times 10^{-4}$ & Down \\
\hline 207540_s_at & SYK & Spleen associated tyrosine kinase & 14 & -1.48 & $2.52 \times 10^{-3}$ & Down \\
\hline 205428_s_at & CALB2 & Calbindin 2 & 13 & 1.25 & $3.93 \times 10^{-6}$ & Up \\
\hline 210001_s_at & SOCS 1 & Suppressor of cytokine signaling 1 & 13 & -1.46 & $4.87 \times 10^{-5}$ & Down \\
\hline 202291_s_at & MGP & Matrix Gla protein & 12 & 1.52 & $5.01 \times 10^{-6}$ & Up \\
\hline 213217_at & ADCY2 & Adenylate cyclase 2 & 12 & 1.96 & $7.75 \times 10^{-4}$ & Up \\
\hline 201069_at & MMP2 & Matrix metallopeptidase 2 & 12 & -2.29 & $2.25 \times 10^{-4}$ & Down \\
\hline 205884_at & ITGA4 & Integrin subunit alpha 4 & 12 & -1.94 & $6.88 \times 10^{-4}$ & Down \\
\hline 201108_s_at & THBS 1 & Thrombospondin 1 & 12 & -1.65 & $2.30 \times 10^{-3}$ & Down \\
\hline 204579_at & FGFR4 & Fibroblast growth factor receptor 4 & 12 & -1.49 & $2.41 \times 10^{-3}$ & Down \\
\hline 219321_at & MPP5 & Membrane protein, palmitoylated 5 & 11 & 1.07 & $6.57 \times 10^{-5}$ & Up \\
\hline 209124_at & MYD88 & Myeloid differentiation primary response 88 & 11 & -1.15 & $9.07 \times 10^{-6}$ & Down \\
\hline 217173_s_at & LDLR & Low density lipoprotein receptor & 11 & -1.06 & $8.12 \times 10^{-5}$ & Down \\
\hline 227486_at & NT5E & 5'-nucleotidase ecto & 10 & -1.64 & $1.19 \times 10^{-4}$ & Down \\
\hline 205751_at & SH3GL2 & SH3-domain GRB2-like 2 & 10 & 1.48 & $1.32 \times 10^{-3}$ & Up \\
\hline 208951_at & ALDH7A1 & Aldehyde dehydrogenase 7 family, member A1 & 10 & -1.21 & $5.77 \times 10^{-5}$ & Down \\
\hline
\end{tabular}

PPI, protein-protein interaction; DEGs, differentially expressed genes; FC, fold change.

identified as the core gene of module 3. Enrichment analyses revealed that ERBB2 was associated with plasma membrane region, cardiovascular system development, angiogenesis, focal adhesion and proteoglycans in cancer. Furthermore, it was associated with ADCY2, FGF10, frizzled-2 (FZD2), FGF3, FGF4, CD44, THBS1, and MMP2, revealing these genes may have joint function in GISTs. Hence, further studies are also required to determine the role of ERBB2 in wild-type GISTs.

MMP2, a member of the matrix metalloproteinase (MMP) gene family, is involved in many cancer pathways and exists in several proteoglycans in cancer. MMP family proteins are zinc-dependent enzymes capable of cleaving components of the extracellular matrix and molecules involved in signal transduction. MMP activity has been implicated in a number of key pathological processes, including tumor growth, progression, metastasis and dysregulated angiogenesis (49). Sebastiano et al (50) reported that MMP2 increases platelet activation by cleaving PAR1 at a noncanonical extracellular site, which induces biased receptor signaling through certain signaling pathways, usually only activated by full PAR1 agonism. Furthermore, it has been reported that the gene interaction between MMP2 and PARP1 may increase the incidence of gastric cancer development and lymph node metastasis (51). In the current study, MMP2 was identified as a downregulated hub gene, enriched in pathways and proteoglycans in cancer of module 3 and associated with ADCY2, ERBB2, FGF10, FZD2, FGF3, FGF4, CD44 and THBS1.

There are several limitations of the present study that require acknowledgement. First, due to the limitations of the gene chip itself, the differentially expressed genes between GIST tissue and normal gastrointestinal tract tissue could not be identified. Second, all predicted results still require confirmation by laboratory data. Finally, a limited number of samples were used in the present study, which should be increased in future studies to improve the reliability of the conclusions drawn.

In conclusion, 546 DEGs were identified in wild-type GISTs, compared with the mutant GIST samples, which may be closely associated with GIST progression. In addition, several key hub DEGs were selected as potential candidate biomarkers for wild-type GISTs, including PIK3CG, IGF1R, HGF, THBS1, ERBB2 and MMP2. However, further verification experiments are required to confirm these results. 
Table IV. Enriched function and pathways of hub genes and selected modules of PPI network.

A, Hub genes

\begin{tabular}{|c|c|c|c|c|}
\hline Term & Description & Count & P-value & Hub genes \\
\hline GO:0005886 & Plasma membrane & 19 & $7.42 \times 10^{-8}$ & $\begin{array}{l}\text { PIK3CG, FGFR4, ADCY2, LDLR, ERBB2, MPP5, } \\
\text { CD40, ITGA4, CDH2, MMP2, VCAM1, IGF1R, } \\
\text { MYD88, CD36, CD44, LRRK2, NT5E, SH3GL2, SYK }\end{array}$ \\
\hline GO:0016020 & Membrane & 11 & $2.53 \times 10^{-4}$ & $\begin{array}{l}\text { PIK3CG, VCAM1, IGF1R, ADCY2, CD36, LDLR, } \\
\text { ERBB2, ITGA4, HGF, CDH2, NT5E }\end{array}$ \\
\hline GO:0070062 & Extracellular exosome & 12 & $4.07 \times 10^{-4}$ & $\begin{array}{l}\text { VCAM1, ALDH7A1, CD44, MPP5, MGP, ITGA4, } \\
\text { CD40, CDH2, THBS1, LRRK2, NT5E, SH3GL2 }\end{array}$ \\
\hline GO:0005737 & Cytoplasm & 16 & $5.71 \times 10^{-4}$ & $\begin{array}{l}\text { PIK3CG, FGFR4, ADCY2, ERBB2, SOCS1, MPP5, } \\
\text { CD40, CDH2, CALB2, ALDH7A1, MYD88, CD44, } \\
\text { LRRK2, NT5E, SH3GL2, SYK }\end{array}$ \\
\hline GO:0005515 & Protein binding & 21 & $1.47 \times 10^{-3}$ & $\begin{array}{l}\text { PIK3CG, FGFR4, LDLR, ERBB2, SOCS1, MPP5, } \\
\text { MGP, HGF, CD40, ITGA4, CDH2, MMP2, IGF1R, } \\
\text { ALDH7A1, MYD88, CD36, CD44, THBS1, LRRK2, } \\
\text { SH3GL2, SYK }\end{array}$ \\
\hline hsa05205 & Proteoglycans in cancer & 7 & $4.89 \times 10^{-11}$ & PIK3CG, IGF1R, CD44, ERBB2, HGF, THBS1, MMP2 \\
\hline hsa04151 & PI3K-Akt signaling pathway & 7 & $1.58 \times 10^{-9}$ & PIK3CG, IGF1R, FGFR4, ITGA4, HGF, THBS1, SYK \\
\hline hsa04510 & Focal adhesion & 6 & $3.19 \times 10^{-9}$ & PIK3CG, IGF1R, ERBB2, ITGA4, HGF, THBS1 \\
\hline hsa04015 & Rap1 signaling pathway & 6 & $3.99 \times 10^{-9}$ & PIK3CG, IGF1R, FGFR4, ADCY2, HGF, THBS1 \\
\hline hsa05200 & Pathways in cancer & 6 & $1.57 \times 10^{-7}$ & PIK3CG, IGF1R, ADCY2, ERBB2, HGF, MMP2 \\
\hline
\end{tabular}

B, Module 1

\begin{tabular}{llrll}
\hline Term & \multicolumn{1}{c}{ Description } & Count & P-value & \\
\hline hsa04151 & PI3K-Akt signaling pathway & 4 & $6.16 \times 10^{-5}$ & IGF1R, FGFR4, JAK3, SYK \\
hsa04550 & $\begin{array}{l}\text { Signaling pathways regulating } \\
\text { pluripotency of stem cells }\end{array}$ & 3 & $1.03 \times 10^{-4}$ & IGF1R, FGFR4, JAK3 \\
& Viral carcinogenesis & 2 & $7.47 \times 10^{-3}$ & FGFR4, SYK \\
hsa05203 & Rap1 signaling pathway & 2 & $7.89 \times 10^{-3}$ & IGF1R, JAK3 \\
hsa04015 & Ras signaling pathway & 2 & $9.15 \times 10^{-3}$ & IGF1R, JAK3 \\
hsa04014 & & & & \\
\hline
\end{tabular}

C, Module 2

\begin{tabular}{lllll}
\hline Term & \multicolumn{1}{c}{ Description } & Count & P-value & Genes \\
\hline hsa04668 & TNF signaling pathway & 2 & $5.09 \times 10^{-4}$ & PIK3CG, MAP3K5 \\
hsa04071 & Sphingolipid signaling pathway & 2 & $6.14 \times 10^{-4}$ & PIK3CG, MAP3K5 \\
hsa04210 & Apoptosis & 2 & $8.16 \times 10^{-4}$ & PIK3CG, MAP3K5 \\
hsa04072 & Phospholipase D signaling pathway & 2 & $8.62 \times 10^{-4}$ & MRAS, PIK3CG \\
hsa05205 & Proteoglycans in cancer & 2 & $1.72 \times 10^{-3}$ & MRAS, PIK3CG \\
\hline
\end{tabular}

D, Module 3

\begin{tabular}{llrll}
\hline Term & \multicolumn{1}{c}{ Description } & Count & P-value & \multicolumn{1}{c}{ Genes } \\
\hline hsa05200 & Pathways in cancer & 7 & $5.55 \times 10^{-8}$ & ADCY2, ERBB2, FGF10, FZD2, MMP2, FGF3, FGF4 \\
hsa05205 & Proteoglycans in cancer & 5 & $1.11 \times 10^{-6}$ & CD44, ERBB2, FZD2, THBS1, MMP2 \\
hsa04015 & Rap1 signaling pathway & 5 & $1.28 \times 10^{-6}$ & ADCY2, FGF10, THBS1, FGF3, FGF4 \\
hsa04512 & ECM-receptor interaction & 3 & $5.86 \times 10^{-5}$ & CD36, CD44, THBS1 \\
hsa05166 & HTLV-I infection & 4 & $8.31 \times 10^{-5}$ & VCAM1, ADCY2, FZD2, CD40
\end{tabular}


Table IV. Continued.

E, Module 4

\begin{tabular}{llrll}
\hline Term & \multicolumn{1}{c}{ Description } & Count & P-value & \multicolumn{1}{c}{ Genes } \\
\hline hsa05205 & Proteoglycans in cancer & 4 & $3.03 \times 10^{-5}$ & WNT5B, ERBB3, WNT9A, HGF \\
hsa04810 & Regulation of actin cytoskeleton & 4 & $3.64 \times 10^{-5}$ & ITGAE, ITGA4, CD14, F2R \\
hsa04151 & PI3K-Akt signaling pathway & 4 & $2.12 \times 10^{-4}$ & MYB, ITGA4, CD14, WNT5B \\
hsa05200 & Pathways in cancer & 4 & $3.71 \times 10^{-4}$ & F2R, ERBB3, WNT9A, WNT5B \\
hsa01100 & Metabolic pathways & 6 & $5.98 \times 10^{-4}$ & CYP3A7, ACSL5, NT5E, PTGIS, ACSS3, ACAA2 \\
\hline
\end{tabular}

Count indicates the enriched gene number in the category. PPI, protein-protein interaction; GO, gene ontology.

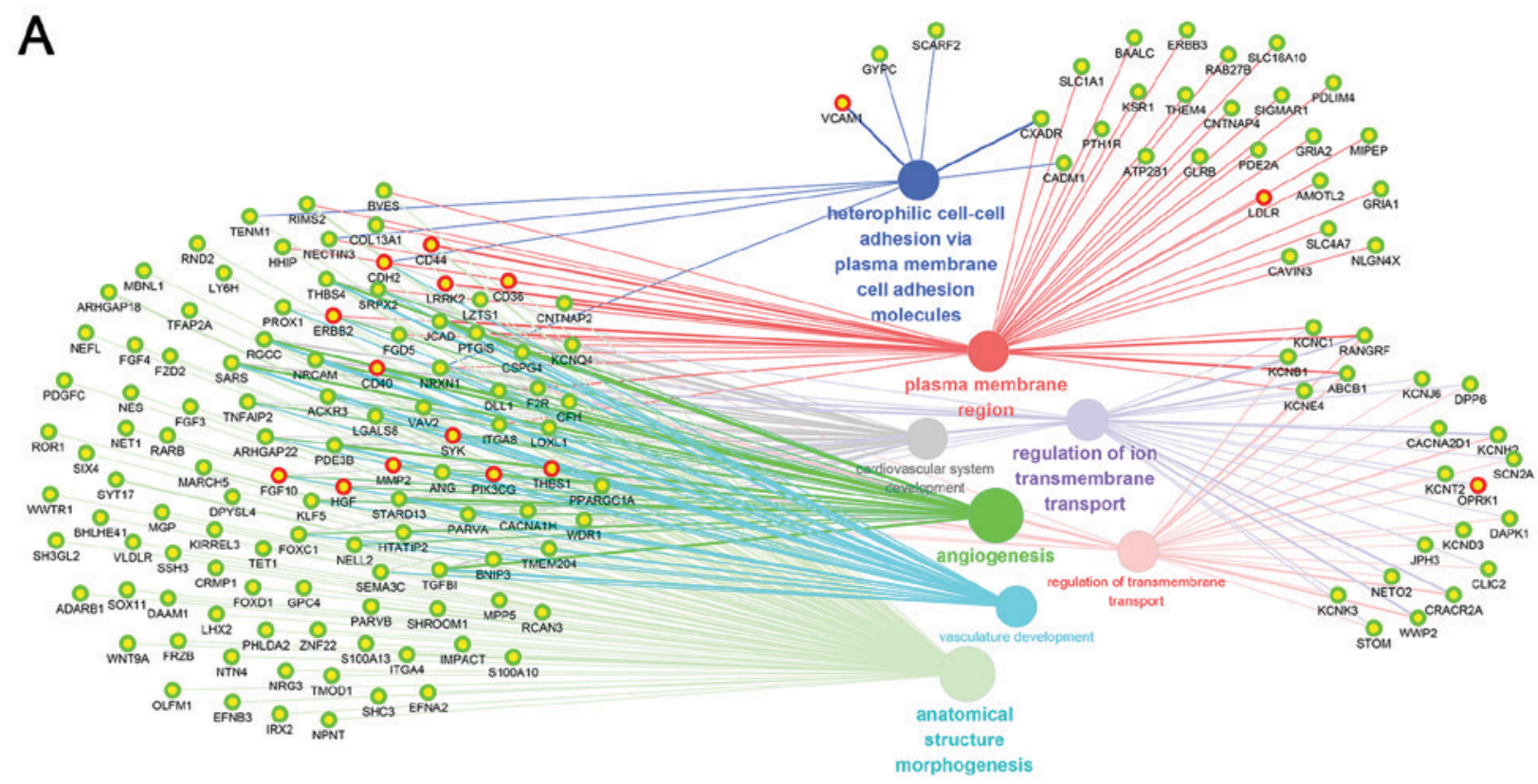

B

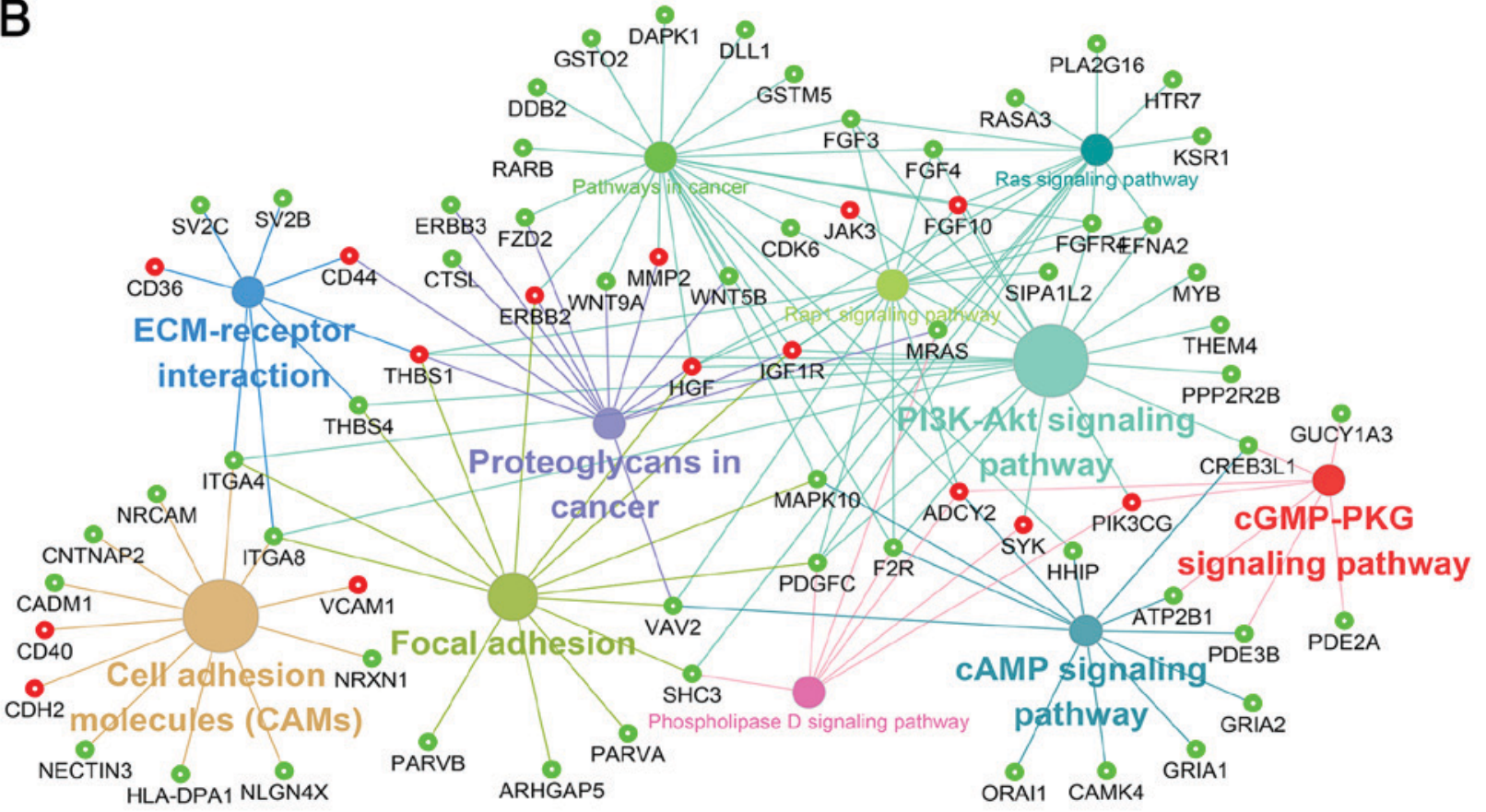

Figure 7. Nodes linking the enriched (A) Gene Ontology function and (B) Kyoto Encyclopedia of Genes and Genomes pathway by hub genes. Solid circles and hollow circles represent each annotation and the DEGs, respectively. Red hollow circles represent hub genes in the protein-protein interaction network. 


\section{Acknowledgements}

The authors are grateful to medical staff of Department of General Surgery, Lanzhou General Hospital of Chinese People's Liberation Army for their support.

\section{Funding}

This study was supported by the Huimin Plan of Ministry of Science and Technology \& Ministry of Finance, P.R. China (grant no. 2012GS620101). the Major Projects of Science and Technology in Gansu Province of P.R. China (grant no. 2011GS04390), the Natural Science Foundation of in Gansu Province of P.R. China (grant no. 1506RJZA309), and the Postdoctoral Research Foundation of P.R. China (grant no. 2015M572710).

\section{Availability of data and materials}

The datasets analyzed in the present study are available from the GEO repository, https://www.ncbi.nlm.nih. gov/geo/query/acc.cgi?acc=GSE17743 and https://www.ncbi. nlm.nih.gov/geo/query/acc.cgi?acc=GSE20708.

\section{Authors' contributions}

The original study design was undertaken by HBL, WJW and ZYJ. Data collection was undertaken JPY and YML. Microarray data were analyzed by WJW and HTL, and appraised by XPH, PC and WWY. Functional and pathway enrichment analysis was undertaken by XPH, PC, WWY and WKC. The draft manuscript was written by WJW, and was reviewed and edited by HTL, JPY, WKC, ZYJ and HBL. All authors have read and approved the final version of the manuscript.

\section{Ethics approval and consent to participate}

Not applicable.

\section{Patient consent for publication}

Not applicable.

\section{Competing interests}

The authors declare that they have no competing interests.

\section{References}

1. Valsangkar N, Sehdev A, Misra S, Zimmers TA, O'Neil BH and Koniaris LG: Current management of gastrointestinal stromal tumors: Surgery, current biomarkers, mutations, and therapy. Surgery 158: 1149-1164, 2015.

2. Ducimetière F, Lurkin A, Ranchère-Vince $D$, Decouvelaere AV, Péoc'h M, Istier L, Chalabreysse P, Muller C, Alberti L, Bringuier PP, et al: Incidence of sarcoma histotypes and molecular subtypes in a prospective epidemiological study with central pathology review and molecular testing. PLoS One 6: e20294, 2011.

3. Patil DT and Rubin BP: Gastrointestinal stromal tumor: Advances in diagnosis and management. Arch Pathol Lab Med 135: 1298-1310, 2011.
4. Joensuu H, Hohenberger P and Corless CL: Gastrointestinal stromal tumour. Lancet 382: 973-983, 2013.

5. Joensuu H, Vehtari A, Riihimaki J, Nishida T, Steigen SE, Brabec P, Plank L, Nilsson B, Cirilli C, Braconi C, et al: Risk of recurrence of gastrointestinal stromal tumour after surgery: An analysis of pooled population-based cohorts. Lancet Oncol 13: 265-274, 2012.

6. Pedroso FE, Raut CP, Xiao H, Yeo CJ and Koniaris LG: Has the survival rate for surgically resected gastric gastrointestinal stromal tumors improved in the tyrosine kinase inhibitor era? Ann Surg Oncol 19: 1748-1758, 2012.

7. Artinyan A, Kim J, Soriano P, Chow W, Bhatia S and Ellenhorn JD: Metastatic gastrointestinal stromal tumors in the era of imatinib: Improved survival and elimination of socioeconomic survival disparities. Cancer Epidemiol Biomarkers Prev 17: 2194-2201, 2008.

8. Corless CL, Barnett CM and Heinrich MC: Gastrointestinal stromal tumours: Origin and molecular oncology. Nat Rev Cancer 11: 865-878, 2011 .

9. Vernuccio F, Taibbi A, Picone D, LA Grutta L, Midiri M, Lagalla R, Lo Re G and Bartolotta TV: Imaging of gastrointesresponse. Anticancer Res 36: 2639-2648, 2016.

10. Heinrich MC, Corless CL, Duensing A, McGreevey L, Chen CJ, Joseph N, Singer S, Griffith DJ, Haley A, Town A, et al: PDGFRA activating mutations in gastrointestinal stromal tumors. Science 299: 708-710, 2003.

11. Ricci R: Syndromic gastrointestinal stromal tumors. Hered Cancer Clin Pract 14: 15, 2016.

12. Joensuu H and DeMatteo RP: The management of gastrointestinal stromal tumors: A model for targeted and multidisciplinary therapy of malignancy. Annu Rev Med 63: 247-258, 2012.

13. Gramza AW, Corless CL and Heinrich MC: Resistance to tyrosine kinase inhibitors in gastrointestinal stromal tumors. Clin Cancer Res 15: 7510-7518, 2009.

14. Ostrowski J, Polkowski M, Paziewska A, Skrzypczak M, Goryca K, Rubel T, Kokoszyñska K, Rutkowski P, Nowecki ZI, Vel Dobosz AJ, et al: Functional features of gene expression profiles differentiating gastrointestinal stromal tumours according to KIT mutations and expression. BMC Cancer 9: 413, 2009.

15. Astolfi A, Nannini M, Pantaleo MA, Di Battista M, Heinrich MC, Santini D, Catena F, Corless CL, Maleddu A, Saponara M, et al: A molecular portrait of gastrointestinal stromal tumors: An integrative analysis of gene expression profiling and high-resolution genomic copy number. Lab Invest 90: 1285-1294, 2010.

16. Irizarry RA, Hobbs B, Collin F, Beazer-Barclay YD, Antonellis KJ, Scherf U and Speed TP: Exploration, normalization, and summaries of high density oligonucleotide array probe level data. Biostatistics 4: 249-264, 2003.

17. R Core Team: R: A language and environment for statistical computing. R Foundation for Statistical Computing, Vienna. http://www.R-project.org/, 2017.

18. Leek JT, Johnson WE, Parker HS, Jaffe AE and Storey JD: The sva package for removing batch effects and other unwanted variation in high-throughput experiments. Bioinformatics 28 : 882-883, 2012.

19. Paradis E, Claude J and Strimmer K: APE: Analyses of phylogenetics and evolution in R language. Bioinformatics 20: 289-290, 2004.

20. Smyth GK, Michaud J and Scott HS: Use of within-array replicate spots for assessing differential expression in microarray experiments. Bioinformatics 21: 2067-2075, 2005.

21. Metsalu T and Vilo J: ClustVis: A web tool for visualizing clustering of multivariate data using principal component analysis and heatmap. Nucleic Acids Res 43: W566-W570, 2015.

22. Huang da W, Sherman BT and Lempicki RA: Systematic and integrative analysis of large gene lists using DAVID bioinformatics resources. Nat Protoc 4: 44-57, 2009.

23. Maere S, Heymans K and Kuiper M: BiNGO: A Cytoscape plugin to assess overrepresentation of gene ontology categories in biological networks. Bioinformatics 21: 3448-3449, 2005.

24. Xie C, Mao X, Huang J, Ding Y, Wu J, Dong S, Kong L, Gao G, Li CY and Wei L: KOBAS 2.0: A web server for annotation and identification of enriched pathways and diseases. Nucleic Acids Res 39 (Web Server Issue): W316-W322, 2011.

25. Szklarczyk D, Morris JH, Cook H, Kuhn M, Wyder S, Simonovic M, Santos A, Doncheva NT, Roth A, Bork P, et al: The STRING database in 2017: Quality-controlled protein-protein association networks, made broadly accessible. Nucleic Acids Res 45: D362-D368, 2017. 
26. Shannon P, Markiel A, Ozier O, Baliga NS, Wang JT, Ramage D, Amin N, Schwikowski B and Ideker T: Cytoscape: A software environment for integrated models of biomolecular interaction networks. Genome Res 13: 2498-2504, 2003.

27. Chin $\mathrm{CH}$, Chen SH, Wu HH, Ho CW, Ko MT and Lin CY: CytoHubba: Identifying hub objects and sub-networks from complex interactome. BMC Syst Biol 8 (Suppl 4): S11, 2014.

28. Bindea G, Mlecnik B, Hackl H, Charoentong P, Tosolini M, Kirilovsky A, Fridman WH, Pagès F, Trajanoski Z and Galon J: ClueGO: A Cytoscape plug-in to decipher functionally grouped gene ontology and pathway annotation networks. Bioinformatics 25: 1091-1093, 2009.

29. Bader GD and Hogue CW: An automated method for finding molecular complexes in large protein interaction networks. BMC Bioinformatics 4: 2, 2003.

30. Ahmad F, Lad P, Bhatia S and Das BR: Molecular spectrum of c-KIT and PDGFRA gene mutations in gastro intestinal stromal tumor: Determination of frequency, distribution pattern and identification of novel mutations in Indian patients. Med Oncol 32: 424, 2015

31. Eccles SA and Welch DR: Metastasis: Recent discoveries and novel treatment strategies. Lancet 369: 1742-1757, 2007.

32. Malanchi I, Santamaria-Martínez A, Susanto E, Peng H, Lehr HA, Delaloye JF and Huelsken J: Interactions between cancer stem cells and their niche govern metastatic colonization. Nature 481: 85-89, 2011.

33. Wain LV, Verwoert GC, O'Reilly PF, Shi G, Johnson T, Johnson AD, Bochud M, Rice KM, Henneman P, Smith AV, et al: Genome-wide association study identifies six new loci influencing pulse pressure and mean arterial pressure. Nat Genet 43 : 1005-1011, 2011

34. Semba S, Itoh N, Ito M, Youssef EM, Harada M, Moriya T, Kimura W and Yamakawa M: Down-regulation of PIK3CG, a catalytic subunit of phosphatidylinositol 3-OH kinase, by $\mathrm{CpG}$ hypermethylation in human colorectal carcinoma. Clin Cancer Res 8: 3824-3831, 2002

35. Li J, Dang Y, Gao J, Li Y, Zou J and Shen L: PI3K/AKT/mTOR pathway is activated after imatinib secondary resistance in gastrointestinal stromal tumors (GISTs). Med Oncol 32: 111, 2015.

36. Yamaguchi R, Harada H and Hirota K: VHL-deficient renal cancer cells gain resistance to mitochondria-activating apoptosis inducers by activating AKT through the IGF1R-PI3K pathway. Tumour Biol 37: 13295-13306, 2016.

37. Ludovini V, Flacco A, Bianconi F, Ragusa M, Vannucci J, Bellezza G, Chiari R, Minotti V, Pistola L, Tofanetti FR, et al: Concomitant high gene copy number and protein overexpression of IGF1R and EGFR negatively affect disease-free survival of surgically resected non-small-cell-lung cancer patients. Cancer Chemother Pharmacol 71: 671-680, 2013.

38. Lee EJ, Kang G, Kang SW, Jang KT, Lee J, Park JO, Park CK, Sohn TS, Kim S and Kim KM: GSTT1 copy number gain and ZNF overexpression are predictors of poor response to imatinib in gastrointestinal stromal tumors. PLoS One 8: e77219, 2013.
39. Tarn C, Rink L, Merkel E, Flieder D, Pathak H, Koumbi D, Testa JR, Eisenberg B, von Mehren $M$ and Godwin AK: Insulin-like growth factor 1 receptor is a potential therapeutic target for gastrointestinal stromal tumors. Proc Natl Acad Sci USA 105: 8387-8392, 2008.

40. Belinsky MG, Rink L, Flieder DB, Jahromi MS, Schiffman JD, Godwin AK and Mehren Mv: Overexpression of insulin-like growth factor 1 receptor and frequent mutational inactivation of SDHA in wild-type SDHB-negative gastrointestinal stromal tumors. Genes Chromosomes Cancer 52: 214-224, 2013

41. Pantaleo MA, Ravegnini G, Astolfi A, Simeon V, Nannini M, Saponara M, Urbini M, Gatto L, Indio V, Sammarini G, et al: Integrating miRNA and gene expression profiling analysis revealed regulatory networks in gastrointestinal stromal tumors. Epigenomics 8: 1347-1366, 2016.

42. Patel MB, Pothula SP, Xu Z, Lee AK, Goldstein D, Pirola RC, Apte MV and Wilson JS: The role of the hepatocyte growth factor/c-MET pathway in pancreatic stellate cell-endothelial cell interactions: Antiangiogenic implications in pancreatic cancer. Carcinogenesis 35: 1891-1900, 2014

43. Hack SP, Bruey JM and Koeppen H: HGF/MET-directed therapeutics in gastroesophageal cancer: A review of clinical and biomarker development. Oncotarget 5: 2866-2880, 2014.

44. Soto-Pantoja DR, Sipes JM, Martin-Manso G, Westwood B, Morris NL, Ghosh A, Emenaker NJ and Roberts DD: Dietary fat overcomes the protective activity of thrombospondin-1 signaling in the Apc(Min/+) model of colon cancer. Oncogenesis 5: e230, 2016.

45. Kashihara H, Shimada M, Yoshikawa K, Higashijima J, Tokunaga T, Nishi M, Takasu C and Ishikawa D: Correlation between thrombospondin-1 expression in non-cancer tissue and gastric carcinogenesis. Anticancer Res 37: 3547-3552, 2017.

46. Huang T, Wang L, Liu D, Li P, Xiong H, Zhuang L, Sun L, Yuan X and Qiu H: FGF7/FGFR2 signal promotes invasion and migration in human gastric cancer through upregulation of thrombospondin-1. Int J Oncol 50: 1501-1512, 2017.

47. Moasser MM: Targeting the function of the HER2 oncogene in human cancer therapeutics. Oncogene 26: 6577-6592, 2007.

48. Van Cutsem E, Sagaert X, Topal B, Haustermans K and Prenen H: Gastric cancer. Lancet 388: 2654-2664, 2016.

49. Roy R, Yang J and Moses MA: Matrix metalloproteinases as novel biomarkers and potential therapeutic targets in human cancer. J Clin Oncol 27: 5287-5297, 2009.

50. Sebastiano M, Momi S, Falcinelli E, Bury L, Hoylaerts MF and Gresele P: A novel mechanism regulating human platelet activation by MMP-2-mediated PAR1 biased signaling. Blood 129: 883-895, 2017.

51. Kim J, Pyun JA, Cho SW, Lee K and Kwack K: Lymph node metastasis of gastric cancer is associated with the interaction between poly(ADP-ribose) polymerase 1 and matrix metallopeptidase 2. DNA Cell Biol 30: 1011-1017, 2011.

This work is licensed under a Creative Commons Attribution-NonCommercial-NoDerivatives 4.0 International (CC BY-NC-ND 4.0) License. 